\title{
Arboreal aperitifs: Space use and activity of a major songbird nest predator in a tropical Thailand forest.
}

Anji D'souza ${ }^{a}, G^{\prime}$ eorge Gale ${ }^{b}$, Benjamin Michael Marshall ${ }^{a}$, Daphawan Khamcha $^{\mathrm{b}}$, Surachit Waengsothorn ${ }^{\mathrm{c}}$, Colin Thomas Strine ${ }^{a}$

\footnotetext{
a School of Biology, Institute of Science, Suranaree University of Technology, Nakhon Ratchasima, Thailand

b Conservation Ecology Program, School of Bioresources and Technology, King Mongkut's University of Technology, Thonburi, Bangkok, Thailand

c Sakaerat Environmental Research Station, Thailand Institute of Scientific and Technological Research, Nakhon Ratchasima, Thailand
}

Corresponding author: Anji D’souza anji.dsouza@gmail.com ; Colin Thomas Strine Colin Strine@sut.ac.th 


\section{ABSTRACT}

Predator-prey interactions are fundamental drivers of population dynamics, yet rarely are both predator and prey species simultaneously studied. Despite being significant, widespread avian nest predators, research on the ecology of Southeast Asian snakes in relation to birds remains scarce. The green cat snake (Boiga cyanea) is a primary nest predator, responsible for $\approx 24 \%$ of forest songbird depredation in Northeast Thailand. We explored both diurnal and nocturnal movements of 14 ( 5 male, 9 female) adult $B$. cyanea with radio-telemetry for an average of $68 \pm 16$ days per individual, between 21 October 2017 and 8 June 2019 in the dry evergreen forest of the Sakaerat Biosphere Reserve (SBR). We quantified area of space use (ha) and activity through motion variance $\left(\sigma_{m}{ }^{2}\right)$ during the study period using dynamic Brownian bridge movement models, and linked our findings to a simultaneously-run avian nest monitoring study, initiated in 2013 within the same forest fragment. On average, movements, space use and activity differed between males and females, and between the avian nesting and non-nesting seasons. Males moved $51.37 \mathrm{~m} /$ day farther than females. They used areas 15.09 ha larger than females, and their activity was $3.91 \sigma_{\mathrm{m}}{ }^{2}$ higher than that of females. In general, individuals moved $50.30 \mathrm{~m} /$ day farther during the nesting season than the nonnesting season. The snakes used areas 9.84 ha larger during the nesting season than the non-nesting season, and their activity during the nesting season was $3.24 \sigma_{\mathrm{m}}{ }^{2}$ higher than that during the non-nesting season. All individuals were exclusively nocturnal, moving throughout the night, and often descending from higher diurnal refugia (>2 $\mathrm{m}$ ) to forage closer to the ground after sunset. Boiga cyanea activity followed a similar trend to that of the recorded nest depredations at SBR. Our study links snake activity to nest depredations in SBR. Our openly-available data may yield further insight when combined with other major avian nest predator species like the congeneric invasive brown tree snake (Boiga irregularis) on the island of Guam.

Keywords: Nest depredation, Boiga cyanea, forest songbird, radio-telemetry, dynamic Brownian bridge movement model. 


\section{INTRODUCTION}

Declining avian populations and species richness degrade ecological processes such as seed dispersal, pollination and invertebrate population control (Sekercioglu et al., 2004). Nest predation exerts strong selection pressures on egg and nestling survival in birds; it is responsible for approximately $80 \%$ of nest failures in most species (DeGregorio et al., 2016c; Martin, 1993; Newmark and Stanley, 2011; Remeš et al., 2012). The extent and consequences of nest depredation on avian ecology have been extensively documented: it influences nest site selection, life histories and community structure (Thompson, 2007).

Reliably identifying and studying nest predators elucidates the complex predator-prey systems, allowing researchers to indirectly infer nest predator behaviour (Croston et al., 2018), while exploring habitat, temporal, and climatic characteristics that might predict nest predation risk (Sperry et al., 2009, 2008; Sperry and Weatherhead, 2009). Studies monitoring nests through cameras (Ribeiro-Silva et al., 2018) and continuous recording video systems (Pierce and Pobprasert, 2007) suggest that snakes are major, widespread avian nest predators (DeGregorio et al., 2016a; Fritts and Rodda, 1998; Robinson et al., 2005). In order to fully understand the factors that facilitate interactions between avian nests and snakes, ecologists ought to study both groups individually and simultaneously (Weatherhead and Blouin-Demers, 2004).

Research on snake-bird dynamics is limited. Snakes are cryptic and occur at low densities, making it difficult to study their foraging ecology (DeGregorio et al., 2014). The most conventional approach for quantifying the activity of cryptic taxa -like snakes, is radio-telemetry (Boback et al., 2020; Crane et al., 2020; DeGregorio et al., 2016c; Whitaker and Shine, 2003). Radio-telemetry has yielded insights into snake spatial, thermal, reproductive, and behavioural ecology (Lutterschmidt, 1994; Reinert et al., 1984; Ujvari and Korsos, 2000), while also revealing links between snake activity and resource availability, predation pressure, and temporal and environmental factors (Greene, 1997).

Few species in North America -the Eastern ratsnake Pantherophis alleghaniensis, the Texas ratsnake $P$. obsoletus, and the Corn snake P. guttatus (DeGregorio et al., 2016b; Sperry et al., 2008; Weatherhead and Charland, 1985) - and the introduced Brown tree snake Boiga irregularis on Guam (Conry, 1988; Rodda et al., 1992; Savidge, 1988) have consistent documentation regarding avian nest predation through radiotelemetry. The impact of the Brown tree snake in Guam highlights the disastrous ecological consequences of uncontrolled (introduced) snake predation on wild nesting bird populations (Fritts and Rodda, 1998; Santana-Bendix, 1994).

In Southeast Asia there is increasing evidence of snakes' prominent role as nest predators. Khamcha et al. (2018) reported that snakes were responsible for $34 \%$ of predation events on 287 monitored nests. More specifically, data suggest that Green cat snake Boiga cyanea is the dominant snake nest predator in the seasonally wet and dry evergreen forests of Northeast Thailand (Angkaew et al., 2019; Khamcha et al., 2018; Khamcha and Gale, 2020; Pierce et al., 2020). Despite the evidence of Southeast Asian snakesparticularly that of nocturnal, arboreal species (Donald et al., 2009; Pierce et al., 2020; Pierce and Pobprasert, 2013)- as nest predators, little to no research exists assessing their movement ecology.

Boiga cyanea (Duméril, Bibron \& Duméril, 1854) is a slender, medium to long bodied nocturnal colubrid ranging throughout Southeast Asia and Indochina. Maximum body length for females is $186 \mathrm{~cm}$, and 153 $\mathrm{cm}$ for males (Chan-ard et al., 2015; Cox et al., 1998). Current knowledge on this species derives from 
occurrence records, natural history notes (Bulian and Bannasan, 1999), captive husbandry, and venom studies (Mackessy, 2002).

Our study attempts to gain insight into the free-ranging and foraging ecology of this primary nest predator as a follow up to the research by Khamcha et al. (2018) and Angkaew et al. (2019) within the same study site. We quantified adult $B$. cyanea space use and movement patterns across the avian nesting and nonnesting seasons within the Sakaerat Biosphere Reserve (SBR), Thailand. We hypothesized that space use and activity would vary between the nesting and non-nesting seasons. We predicted that (1) B. cyanea activity would be higher during the avian nesting season at SBR (Khamcha et al., 2018), and (2) B. cyanea space use would be larger during the avian non-nesting season.

\section{MATERIAL AND METHODS}

\subsection{Study area}

We conducted our research between 21 October 2017 and 8 June 2019 within the dry evergreen forests of the core area of the Sakaerat Biosphere Reserve (SBR; UNESCO-MAB Biosphere Reserve; Fig. 1), Nakhon Ratchasima Province, Thailand $\left(14.44-14.55^{\circ} \mathrm{N}, 101.88-101.95^{\circ} \mathrm{E}\right)$. The core area of the SBR covers approximately 5,700 ha of protected area between $280 \mathrm{~m}$ and $762 \mathrm{~m}$ elevations. The core area encompasses a matrix of dry evergreen forest, open dry dipterocarp forest, transitional mixed deciduous vegetation, and operational buildings of the field research station that occupy less than $2 \%$ of the core area. Hopea ferrea, Hopea odorata and Hydnocarpus ilicifolia dominate the dry evergreen forest, while Shorea obtusa, Shorea siamensis, Dipterocarpus intricatus and Gardenia sootepensis are predominant characters of the dry dipterocarp forest. Marshall et al. (2020) summarized the annual seasonal weather patterns within the core area of SBR between 2012 and 2018 using a cluster analysis, as follows: the hot season (16 March to 30 September) averaging $33.8 \pm 2.8^{\circ} \mathrm{C}$ and $2.5 \pm 7.9 \mathrm{~mm} /$ day rainfall; the wet season (1 October to 31 December) $29.9 \pm 2.2^{\circ} \mathrm{C}$ and $5.9 \pm 11.1 \mathrm{~mm} /$ day rainfall; and the dry season (1 January to $15 \mathrm{March}) 29.0 \pm 3.5^{\circ} \mathrm{C}$ and $0.2 \pm 0.8 \mathrm{~mm} /$ day rainfall. However, we use Khamcha et al.'s (2018) definitions of wet (May to October) and dry (November to April) seasons for comparison, as they seem more biologically significant to the birds' activity season at SBR. 


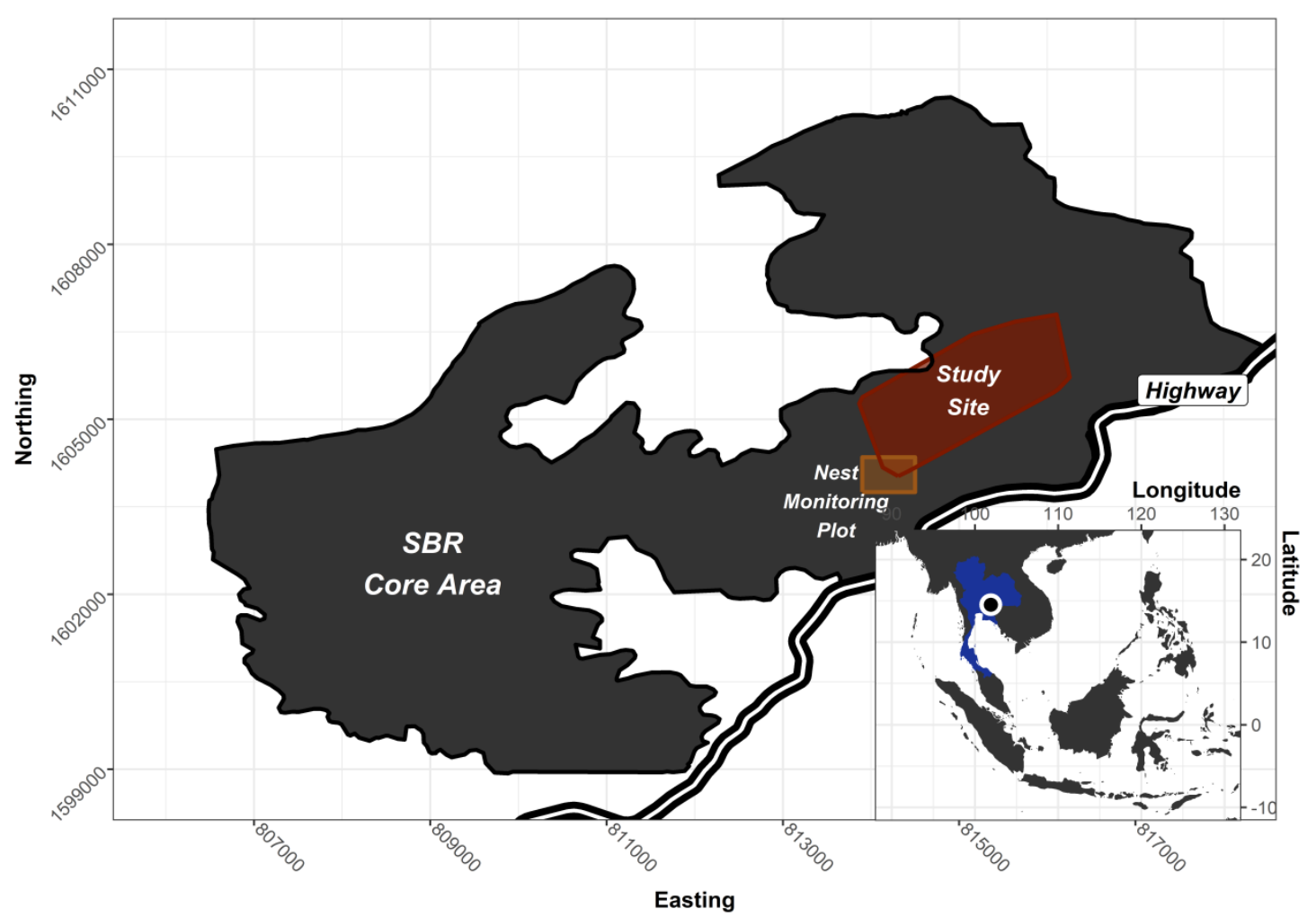

Fig. 1. Study location. The main map shows the Sakaerat Biosphere Reserve core area. The radio-tracking study site is highlighted in red. The 36-ha nest monitoring plot is highlighted in orange. The main map is projected using UTM zone $47 \mathrm{~N}$, with scales in meters and north orientation. The inset map shows the study location relative to Southeast Asia, with scales in degrees.

\subsection{Study sample}

We used manual radio-telemetry to investigate Boiga cyanea movement patterns and space use. We obtained individuals for our research through opportunistic captures, sighting notifications from other researchers, and 904 hours of targeted nocturnal surveys in the dry evergreen forest. We measured total body lengths and mass for all captured individuals and determined their sex with cloacal probing (Schaefer, 1934). Upon collecting morphometric data, we assessed each individual's suitability for radio-telemetry. The selection criteria required the individuals to be adults large enough to sustain an implantation surgery and accommodate a 1.8g VHF radio-transmitter (Model BD-2T or BD-2, Holohil Systems Incorporated, Ontario, Canada) in their coelomic cavity. We ensured that the radio-transmitter's mass was less than $3 \%$ of that of the snakes. We only chose to surgically implant adult B. cyanea that were found within the dry evergreen forests of the core area of SBR. We also excluded adults that were excessively slender (i.e., visible neural arch or $<9 \mathrm{~mm}$ girth at $75 \%$ snout-vent length), gravely injured or heavily gravid from being a part of the study sample.

A qualified wildlife veterinarian from Nakhon Ratchasima Zoo performed all surgeries, in accordance with Thai law. We administered isoflurane inhalation anesthetic to the snakes undergoing surgery, and followed a modified surgical technique described by Reinert and Cundall (1982). We released the implanted individuals as close as possible $(\leq 20 \mathrm{~m})$ to their capture location within 12 hours post-surgery to allow for recovery and thermoregulation. 


\subsection{Radio-telemetry}

The BD-2T and BD-2 model Holohil radio-transmitters ideally provide a $500-1000 \mathrm{~m}$ signal range (Holohil Systems Incorporated, Ontario, Canada). However, the topography at SBR typically reduced signal range to $150-250 \mathrm{~m}$. We located all individuals once each day during daylight hours between 21 October 2017 and 8 June 2019. We also radio-tracked the snakes during night hours after sunset but before sunrise from 14 March to 3 September, 2018, and from 15 January to 8 June, 2019. We defined fixes as the number of times we located an individual, regardless of whether it had moved or not. We defined relocations as the number of times we located an individual in a different location from its previous one.

During night-time tracks, we located each individual between one to three times at approximately fourhour intervals, every alternate night to assess the nocturnal activity and movement patterns. Exceptional circumstances during which we failed to collect data included: equipment malfunction, staff unavailability, adverse weather conditions, individuals awaiting transmitter replacement at the research facility, and inability to detect radio-signal for extended periods of time despite intensive search effort.

We estimated locations via the homing method (Amelon et al., 2009) attempting visual observations whenever feasible, primarily at night, in order to confirm the accuracy of the telemetered location. We aimed to minimize disturbance by moving discreetly through their immediate surroundings and by limiting the amount of time spent in their vicinity after pinpointing animals. We located the snakes' daytime refugia during diurnal locations, while we assessed their activity during nocturnal fixes.

For every fix (including non-moves), we recorded the snake's location with hand-held global positioning system (GPS) units (Garmin GPSMAP 64s, Garmin Ltd., United States) using the Universal Transverse Mercator (UTM; 47N World Geodetic System 84) coordinate reference system. We identified the snake's position -whether arboreal $(>0 \mathrm{~m})$ or terrestrial $(\leq 0 \mathrm{~m})$, and measured its height off the ground $(\mathrm{m})$ with a measuring tape or rangefinder (Nikon Forestry Pro II, Nikon Inc., United States) for each visual observation. We documented its behaviour -whether stationary or moving, through radio-signal patterns (i.e. marked fluctuations in signal strength) or visual confirmations.

\subsection{Nest monitoring}

To explore the relationship between avian nest depredation and B. cyanea movement, we were granted access to nest predation records documented at the Sakaerat Biosphere Reserve by researchers from King Mongkut's University of Technology Thonburi (KMUTT), Thailand. The nest predation data were collected within a 36-ha, permanent, nest monitoring plot in the dry evergreen forest (Khamcha et al., 2018; Khamcha and Gale, 2020; Somsiri et al., 2020) via continuous-recording video systems adapted from Pierce and Pobprasert (2007). The video systems were active throughout the nesting seasons between 2013 and 2019, monitoring 12 species of forest birds' nests.

The dataset presents the bird species with nests depredated by $B$. cyanea, the nest heights, the date the nests were found and filmed, and the date, time and geographic coordinates of the predation events. We defined the avian nesting season in the SBR as the period between the date of discovery of the first avian nest and the date of the last nest depredation or nest abandonment. In 2018, the avian nesting season lasted from 4 February until 31 July. In 2019, the avian nesting season lasted from 4 March until 5 August. When considering the overall study period, we defined the avian nesting season as that spanning between 4 February and 5 August. 


\subsection{Software and data}

We used $R$ v.4.0.3 (R Core Team, 2020) and R Studio v.1.3.1093 (R Studio Team, 2020) as the front-end for data manipulation, analyses, and visualization. For data manipulation, we used packages: dplyr v.0.8.5 (Wickham et al., 2020) to prepare our data for analysis, lubridate v.1.7.8 (Grolemund and Wickham, 2011) to work with date and time formats, tidybayes v.2.1.1 (Kay, 2020) to compose data for Bayesian methods, reshape2 v.1.4.4 (Wickham, 2007) to transform data into desired formats, raster v.3.1.5 (Hijmans et al., 2020) to read and manipulate spatial data, rgeos v.0.5.3 (Bivand et al., 2020) to read and manipulate geographic data.

For data analyses, we used packages: move v.4.0.0 (Kranstauber et al., 2020) to analyze animal movement data, brms v.2.14.0 (Bürkner, 2017) to assess Bayesian generalized (non)linear multivariate multi-level models, performance v.0.4.7 (Lüdecke et al., 2020) to assess the quality of regression models, bestNormalize v.1.5.0 (Peterson and Cavanaugh, 2020) to find the best normalizing transformation, overlap v.0.3.3 (Ridout and Linkie, 2009) to quantify overlap between species' activity periods, arm v.1.11.1 (Gelman et al., 2020) to analyze regression models, wiqid v.0.3.0 (Meredith et al., 2020) to estimate maximum likelihood and wildlife population parameters, adehabitatHR v.0.4.18 (Calenge, 2006) to assess habitat selection, recurse v.1.1.2 (Bracis et al., 2018) to analyze animal trajectory data, cluster v.2.1.0 (Maechler et al., 2019) to group and analyze data based on similarities, MASS v.7.3.53 (Venables and Ripley, 2002) to test for significance using Pearson's Chi-squared test, astroFns v.4.1.0 (Harris, 2012) to convert hours to radians.

For data visualization, we used packages: ggplot2 v.3.3.0 (Wickham, 2016), ggpubr v.0.4.0 (Kassambara, 2020), scales v.1.1.1 (Wickham and Seidel, 2020), scico v.1.2.0 (Pedersen and Crameri, 2020), ggspatial v.1.1.3 (Dunnington and Thorne, 2020), gtable v.0.3.0 (Wickham and Pedersen, 2019), cowplot v.1.0.0 (Wilke, 2020a), bayesplot v.1.7.2 (Gabry and Mahr, 2020), ggridges v.0.5.2 (Wilke, 2020b), ggtext v.0.1.0 (Wilke, 2020c), plotrix v.3.7.8 (Lemon et al., 2020).

Movement, activity, and dBBMM outputs and R scripts are available online at Open Science Framework (https://osf.io/6yrbg/). Movement data were additionally uploaded on Movebank (Movebank ID: 1418023557).

\subsection{Analyses}

We used the dplyr package (Wickham et al., 2020) to summarize data into means and their standard errors, or medians and their interquartile range (IQR) when data were non-normal or had major outliers. We used a Bayesian test of difference with Markov chain Monte Carlo (MCMC) simulations for inference on posterior distributions between groups as opposed to traditional frequentist $\mathrm{t}$-tests and non-parametric tests as our sample sizes were small. We report their 95\% Bayesian credible intervals (BCrl) using the Highest Density Interval (HDI) method, and their point estimates as the true difference between group means. We checked for MCMC convergence by graphically assessing their trace plots. We report a Pearson's Chi-Squared test to assess significance $(p=0.05)$ between moving and stationary behaviours during the nesting and non-nesting seasons.

We estimated horizontal movements by calculating the mean daily displacement (MDD) for each individual. We defined MDD as the ratio between the sum of the Euclidean distances between consecutive fixes and the total number of days the individual was radio-tracked. We estimated space use during the study period 
and movement patterns using dynamic Brownian bridge movement models (dBBMM) with the move package (Kranstauber et al., 2020). The dynamic Brownian bridge movement models quantify an individual's occurrence distribution based on its movement path during the study period (Kranstauber et al., 2012). This method originally analyzed GPS telemetry data on mammals and birds (Kranstauber et al., 2012). However, more recently VHF telemetry data applications on reptiles have become apparent (Knierim et al., 2019; Silva et al., 2018; Smith et al., 2020). Unlike traditional space use estimators, such as minimum convex polygons (MCP) and kernel density estimators (KDE), dBBMMs simultaneously account for spatial and temporal autocorrelation, GPS uncertainty around each location, and are more robust to irregular sampling intervals.

Additionally, dBBMMs provide estimates for an animal's mobility -referred to as the Brownian motion variance $\left(\sigma_{m}^{2}\right)$. This metric describes heterogeneous movement behaviour or movement diffusion along an individual's movement trajectory (Kranstauber et al., 2012), based on user-defined, biologically significant moving window and margin sizes. The moving windows and margins help estimate motion variance for subsections of the movement trajectory, thus facilitating detection of gradual and sudden changes in movement behaviour. After testing dBBMMs with larger window and margin sizes (Tables: A.1, A.2, A.3), we chose to set the window size to 9 data points to detect variations in behavioural states between 3-day periods -approximately the average time an individual would spend stationary. We set the margin size to 3 data points to detect variations between active and inactive behaviours; then specified the telemetry error associated with each data point as the mean GPS accuracy of all telemetered locations. The $90 \%, 95 \%$ and 99\% dBBMM isopleth contours delineate snake occurrence distributions during the study period (example:

Fig. A.2, Fig. A.3).

We ran a Bayesian regressive model with brms package (Bürkner, 2017) to assess the seasonal and sex impacts on motion variance. We opted for a Bayesian approach because the assumptions for the normality of residuals are relaxed and the estimates are more conservative. We used the bestNormalize package (Peterson and Cavanaugh, 2020) to shift motion variance values to a Gaussian distribution. To account for the autocorrelated structure of motion variance data, we used a third order autoregressive term (matching our selected margin size) in brms. We used motion variance as the response variable, season (avian nesting and non-nesting) and sex (male and female) as the population variables, and individual ID as a group effect [motion variance $\sim$ season $+\operatorname{sex}+(1 \mid I D)+\operatorname{ar}(p=3)]$. We used the package's default priors (Student $\mathrm{t}$ distribution: $\mathrm{df}=3, \mathrm{mu}=0$, sigma $=2.5$ ) as we had no reliable prior information to base our motion variance on for this species. We ran 5 chains with 5000 iterations with 1000 iterations of warmup and determined model convergence with trace plots and when rHat neared one (Gelman and Rubin, 1992). We coded female $B$. cyanea during the avian nesting season as the intercept, and the non-nesting season and males as the other two coefficients. We used the bayesplot package (Gabry and Mahr, 2020) as a visual diagnosis for autocorrelation of all model variables, and for posterior predictive checking of observed data compared to simulated data. We used the performance package (Lüdecke et al., 2020) to derive the Rsquared $\left(R^{2}\right)$ regression metric to estimate the proportion of variation explained by the predictor variables.

\section{RESULTS}

\subsection{Radio-telemetry}

We radio-tracked a total of 14 adult Boiga cyanea -5 males and 9 females. We gathered a total of 1317 fixes and 640 relocations. We recorded 907 fixes during daylight hours, and 410 fixes at night. We recorded 
780 fixes during the avian nesting season (diurnal: 480; nocturnal: 300), and 537 fixes during the nonnesting season (diurnal: 427; nocturnal: 110).

Tracking durations varied considerably among individuals. Most heterogeneity in duration resulted from individual loss: premature transmitter failures $(n=8)$, inexplicable deaths $(n=3)$, predations $(n=2)$, and inaccessible recapture locations $(n=1)$. Of the 14 radio-tracked $B$. cyanea, we were able to successfully recapture and re-implant only 2 individuals -F01 and M04.

We only report movement and dBBMM summaries for 12 individuals, omitting F06 and F07 with 18 and 7 day tracking durations respectively (Table 1 ). We were unable to derive dBBMM outputs for both individuals given our window (9) and margin sizes (3). 
Table 1. Tracking summaries of radio-tracked Boiga cyanea between 21 October 2017 and 8 June 2019.

\begin{tabular}{|c|c|c|c|c|c|c|c|c|c|}
\hline ID & SVL (mm) & $\begin{array}{l}\text { Start date } \\
(\mathrm{d} / \mathrm{m} / \mathrm{y})\end{array}$ & $\begin{array}{l}\text { End date } \\
(\mathrm{d} / \mathrm{m} / \mathrm{y})\end{array}$ & Days tracked & Fixes & Relocations & Time lag (hr) & $\begin{array}{l}\text { Revisit frequency } \\
\text { (days) }\end{array}$ & $\begin{array}{c}\text { Time stationary } \\
\text { (days) }\end{array}$ \\
\hline F01 & 914 & $21 / 10 / 2017$ & $17 / 02 / 2018$ & 119 & 102 & 72 & $28.22 \pm 2.7$ & $18.80 \pm 3.05$ & $2.18 \pm 0.30$ \\
\hline F02 & 973 & $23 / 10 / 2017$ & $13 / 01 / 2018$ & 82 & 79 & 40 & $25.18 \pm 0.92$ & $11.10 \pm 0.87$ & $5.75 \pm 0.65$ \\
\hline F03 & 1086 & $28 / 12 / 2017$ & $01 / 05 / 2018$ & 124 & 146 & 69 & $20.51 \pm 0.9$ & $16.60 \pm 1.21$ & $3.04 \pm 0.23$ \\
\hline M01 & 1046 & $23 / 03 / 2018$ & 06/07/2018 & 105 & 134 & 59 & $18.96 \pm 1.03$ & $22.60 \pm 1.62$ & $9.59 \pm 1.27$ \\
\hline M02 & 1200 & 03/03/2018 & 08/04/2018 & 36 & 48 & 25 & $18.36 \pm 1.13$ & $2.28 \pm 0.23$ & $1.60 \pm 0.18$ \\
\hline M03 & 1150 & $24 / 04 / 2018$ & $28 / 07 / 2018$ & 95 & 129 & 83 & $17.81 \pm 1.17$ & $12.30 \pm 2.46$ & $1.69 \pm 0.23$ \\
\hline F04 & 1204 & $11 / 08 / 2018$ & 04/09/2018 & 24 & 44 & 28 & $13.53 \pm 1.02$ & $2.21 \pm 1.06$ & $1.60 \pm 0.30$ \\
\hline M04 & 960 & $06 / 11 / 2018$ & 08/06/2019 & 214 & 395 & 168 & $13.03 \pm 0.5$ & $28.10 \pm 1.35$ & $2.25 \pm 0.13$ \\
\hline F05 & 1205 & $12 / 11 / 2018$ & $16 / 01 / 2019$ & 65 & 73 & 33 & $21.6 \pm 0.98$ & $11.80 \pm 1.15$ & $5.73 \pm 0.71$ \\
\hline F06 & 1114 & $12 / 11 / 2018$ & $01 / 12 / 2018$ & 18 & 25 & 2 & $18.45 \pm 1.31$ & $0.61 \pm 0.08$ & $5.49 \pm 0.62$ \\
\hline F07 & 1028 & 23/03/2019 & $30 / 03 / 2019$ & 7 & 15 & 4 & $11.83 \pm 2.29$ & $1.15 \pm 0.15$ & $1.49 \pm 0.09$ \\
\hline F08 & 952 & 07/04/2019 & 29/04/2019 & 22 & 46 & 18 & $11.55 \pm 1.91$ & $2.70 \pm 0.00$ & $2.22 \pm 0.34$ \\
\hline F09 & 1050 & 27/04/2019 & $24 / 05 / 2019$ & 27 & 48 & 16 & $13.9 \pm 1.51$ & $6.79 \pm 1.14$ & $3.00 \pm 0.39$ \\
\hline M05 & 1174 & $19 / 05 / 2019$ & 08/06/2019 & 19 & 33 & 23 & $14.59 \pm 2.19$ & - & $0.54 \pm 0.15$ \\
\hline Females & $1058 \pm 35$ & $21 / 10 / 2017$ & $24 / 05 / 2019$ & $54 \pm 15$ & $64 \pm 14$ & $31 \pm 8$ & $20.57 \pm 0.64$ & $7.97 \pm 2.29$ & $3.39 \pm 0.59$ \\
\hline Males & $1106 \pm 45$ & $23 / 03 / 2018$ & 08/06/2019 & $94 \pm 34$ & $148 \pm 65$ & $72 \pm 27$ & $15.35 \pm 0.41$ & $16.32 \pm 5.71$ & $3.13 \pm 1.64$ \\
\hline Total & $1075 \pm 27$ & $21 / 10 / 2017$ & 08/06/2019 & $68 \pm 16$ & $94 \pm 26$ & $46 \pm 12$ & $17.63 \pm 0.37$ & $10.54 \pm 2.49$ & $3.29 \pm 0.66$ \\
\hline
\end{tabular}

*SVL: Snout-to-Vent Length; SVL, days tracked, fixes, relocations, time lag(as seen in Fig. A1), revisit frequency and time stationary for females, males and the whole sample are reported as means \pm standard error. 


\subsection{Space use}

\subsubsection{Horizontal movements}

The mean daily displacement (MDD; Table 2) for male and female snakes together was short -just over 55 $\mathrm{m} /$ day. Males moved significantly longer daily distances than females (Point Estimate of Difference (PED): 51.37 m/day; 95\% Bayesian Credible Interval (BCrl): 5.05 - 97.9). Snakes moved significantly greater daily distances on average during the avian nesting season compared to the non-nesting season (PED: 50.30 $\mathrm{m} /$ day; $95 \%$ BCrl: 21.1 - 79.1). We caution that the samples may not be independent, as individuals may have influenced other individuals' movements by increasing or reducing them.

Table 2. Movement summaries of radio-tracked Boiga cyanea.

\begin{tabular}{ccccccc}
\hline Snake ID & SVL (mm) & $\begin{array}{c}\text { MDD (m/day) } \\
\text { Nesting }\end{array}$ & $\begin{array}{c}\text { MDD } \\
\text { (m/day) } \\
\text { Non-nesting }\end{array}$ & $\begin{array}{c}\text { MDD } \\
(\mathbf{m} / \text { day })\end{array}$ & $\begin{array}{c}\text { Max. distance } \\
\text { moved }(\mathbf{m})\end{array}$ & $\begin{array}{c}\text { Max. days } \\
\text { stationary }\end{array}$ \\
\hline F01 & 914 & 10 & 25 & 23 & 161 & 11 \\
F02 & 973 & - & 15 & 15 & 132 & 24 \\
F03 & 1086 & 52 & 9 & 38 & 260 & 13 \\
F04 & 1204 & - & 28 & 28 & 68 & 3 \\
F05 & 1205 & - & 29 & 29 & 400 & 23 \\
F08 & 952 & 62 & - & 62 & 402 & 4 \\
F09 & 1050 & 50 & - & 50 & 167 & 9 \\
\hline M01 & 1046 & 100 & - & 100 & 385 & 33 \\
M02 & 1200 & 46 & - & 46 & 190 & 4 \\
M03 & 1150 & 115 & - & 115 & 583 & 4 \\
M04 & 960 & 87 & 20 & 50 & 245 & 11 \\
M05 & 1174 & 121 & - & 121 & 524 & 1 \\
\hline Females & $1055 \pm 44$ & $43.29 \pm 11.46$ & $21.18 \pm 3.97$ & $35.08 \pm 6.11$ & $227.14 \pm 49.74$ & $12 \pm 3$ \\
Males & $1106 \pm 45$ & $93.65 \pm 13.22$ & 20 & $86.33 \pm 15.95$ & $385.4 \pm 76.21$ & $11 \pm 6$ \\
Total & $1076 \pm 31$ & $71.27 \pm 12.2$ & $21.05 \pm 3.25$ & $56.44 \pm 10.41$ & $293.08 \pm 47.12$ & $12 \pm 3$ \\
\hline
\end{tabular}

*SVL: Snout-to-Vent Length; MDD: Mean Daily displacement; Max. distance moved (m): farthest distance travelled between consecutive diurnal fixes.

\subsubsection{Vertical movements}

We confirmed 158 height observations, of which 48 in daylight and 110 at night. During the day, all height observations were $10 \mathrm{~m}$ or below (range: $0-10$ ). Of the 48 of 907 total daylight fixes during our study, the snakes sheltered on average in the understory $(\bar{x}=3.26 \pm 0.48 \mathrm{~m} ; n=31$; on ground observations were not included in arboreal refugia average calculations). Proximity to the snakes and our detection ability influenced whether we could confirm daytime refugia heights, so we cannot provide reliable statistics on higher diurnal refugia. We feel confident in stating that for the remaining 859 diurnal fixes, the snakes were located at heights over $2 \mathrm{~m}$ above the ground.

The snakes generally foraged close to the ground at night (median height: $1.5 \mathrm{~m}$; IQR: 3.5 ). We visually confirmed 102 night-time heights of 300 night-time fixes during the avian nesting season (Fig. 2B). The 
snakes moved closer to the ground during the avian nesting season (median height: $1.5 \mathrm{~m}$; IQR: 3) compared to the non-nesting season (median height: 3.25; IQR: 5.42).

The avian nests monitored $(n=856)$ at SBR between 2013 and 2019 were all below $25 \mathrm{~m}$ (median height: 1.5; IQR: 4.51; Fig. 2A). All records of nests depredated by B. cyanea $(n=53)$ between 2013 and 2019 were below $6 \mathrm{~m}$ (median height: $1 \mathrm{~m}$; IQR: 1).

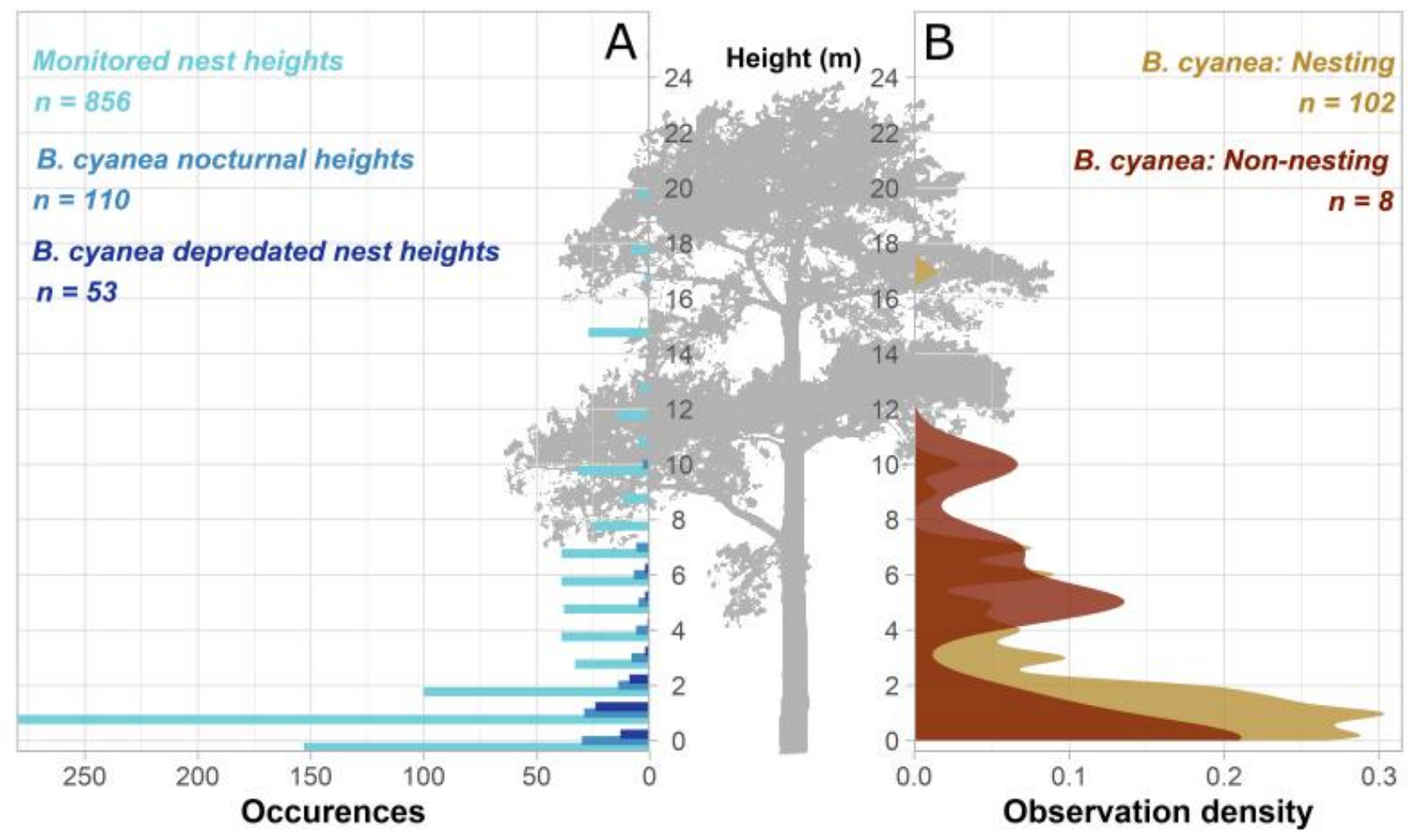

Fig. 2. Height comparisons of Boiga cyanea activity and monitored avian nests at SBR. A) Histogram illustrating monitored nest heights $(2013-2019), B$. cyanea night-time movement heights (2017.10.21 2019.06.08), and B. cyanea depredated nest heights (2013 - 2019). B) Density plot comparing B. cyanea night-time movement heights during the avian nesting seasons and non-nesting seasons between 2017.10.21 and 2019.06.08.

\subsubsection{Occurrence distribution}

In general, males used substantially larger areas than females (PED: 15.09 ha; 95\% BCrl: -3.34 - 33; Table 3). We only tracked one male during the avian non-nesting season, so we cannot infer differences in male space use between the nesting and non-nesting seasons. Females used similar areas between the nesting and non-nesting seasons (PED: 1.80 ha; $95 \%$ BCrl: -3.43-7.02). However, when combining both males and females, snakes used significantly larger areas during the nesting season than the non-nesting season (PED: 9.84; 95\% BCrl: $-0.02-20$ ). 
Table 3. Space use summaries of radio-tracked Boiga cyanea.

\begin{tabular}{|c|c|c|c|c|c|c|c|c|}
\hline Snake ID & Days tracked & $\begin{array}{l}\text { dBBMM } 90 \% \\
\text { (ha) }\end{array}$ & $\begin{array}{l}\text { dBBMM 95\% } \\
\text { (ha) }\end{array}$ & $\begin{array}{c}\text { dBBMM } 99 \% \\
\text { (ha) }\end{array}$ & $\begin{array}{c}\text { Days } \\
\text { tracked } \\
\text { Nesting }\end{array}$ & $\begin{array}{c}\text { dBBMM 95\% } \\
\text { (ha) } \\
\text { Nesting }\end{array}$ & $\begin{array}{c}\text { Days } \\
\text { tracked } \\
\text { Non-nesting }\end{array}$ & $\begin{array}{c}\text { dBBMM 95\% } \\
\text { (ha) } \\
\text { Non-nesting }\end{array}$ \\
\hline F01 & 119 & 1.66 & 2.13 & 3.17 & 13 & 0.32 & 105 & 2.19 \\
\hline F02 & 82 & 0.89 & 1.48 & 2.70 & - & - & 82 & 1.48 \\
\hline F03 & 124 & 4.09 & 6.31 & 11.40 & 86 & 7.55 & 37 & 0.09 \\
\hline F04 & 24 & 0.56 & 0.84 & 1.45 & - & - & 24 & 0.84 \\
\hline F05 & 65 & 1.21 & 4.45 & 12.34 & - & - & 65 & 4.45 \\
\hline F08 & 22 & 2.52 & 3.84 & 7.20 & 22 & 3.84 & - & - \\
\hline F09 & 27 & 1.85 & 2.70 & 4.80 & 27 & 2.70 & - & - \\
\hline M01 & 105 & 27.48 & 37.57 & 59.78 & 105 & 37.57 & - & - \\
\hline M02 & 36 & 1.99 & 2.85 & 4.21 & 36 & 2.85 & - & - \\
\hline M03 & 95 & 18.35 & 24.81 & 39.55 & 95 & 24.81 & - & - \\
\hline M04 & 214 & 3.97 & 5.29 & 8.74 & 96 & 6.3 & 117 & 2.73 \\
\hline M05 & 19 & 15.84 & 20.32 & 29.80 & 19 & 20.32 & - & - \\
\hline Females & $66 \pm 17$ & $1.82 \pm 0.44$ & $3.11 \pm 0.72$ & $6.15 \pm 1.63$ & $37 \pm 17$ & $3.60 \pm 1.51$ & $63 \pm 15$ & $1.81 \pm 0.75$ \\
\hline Males & $94 \pm 34$ & $13.53 \pm 4.73$ & $18.17 \pm 6.43$ & $28.42 \pm 10.2$ & $70 \pm 18$ & $18.37 \pm 6.33$ & 117 & 2.73 \\
\hline Total & $78 \pm 17$ & $6.7 \pm 2.55$ & $9.38 \pm 3.38$ & $15.43 \pm 5.25$ & $55 \pm 13$ & $11.81 \pm 4.27$ & $72 \pm 15$ & $1.96 \pm 0.63$ \\
\hline
\end{tabular}

*dBBMM: Dynamic Brownian bridge movement model space use estimate; Nesting: avian nesting season; Non-nesting: avian non-nesting season. 


\subsection{Temporal activity patterns}

\subsubsection{Seasonal activity}

We use the dBBMM motion variance $\left(\sigma_{m}{ }^{2}\right)$ as a proxy for snake foraging activity. Males generally displayed higher activity than females (PED: $3.91 \sigma_{\mathrm{m}}{ }^{2} ; 95 \%$ BCrl: $-0.12-8.16$; Table 4; Fig. 3). Because we only tracked one male during the avian non-nesting season, we cannot infer differences in male activity between the nesting and non-nesting seasons. Females did not exhibit much difference in activity between the nesting and non-nesting seasons (PED: $1.08 \sigma_{\mathrm{m}}{ }^{2} ; 95 \% \mathrm{BCrl}:-0.52-2.73$ ). However, in general, tracked snakes were significantly more active during the nesting season than the non-nesting season (PED: $3.24 \sigma_{\mathrm{m}}{ }^{2} ; 95 \% \mathrm{BCrl}$ : $0.874-5.56)$.

Table 4. Motion variance (as seen in Fig. A.4) summaries of radio-tracked Boiga cyanea.

\begin{tabular}{ccccccc}
\hline Snake ID & $\begin{array}{c}\text { Days } \\
\text { Tracked }\end{array}$ & $\boldsymbol{\sigma}_{\mathrm{m}}{ }^{2} \pm \mathbf{S E}$ & $\begin{array}{c}\text { Days } \\
\text { Nesting }\end{array}$ & $\begin{array}{c}\boldsymbol{\sigma}_{\mathrm{m}}{ }^{2} \pm \mathbf{S E} \\
\text { Nesting }\end{array}$ & $\begin{array}{c}\text { Days } \\
\text { Non-nesting }\end{array}$ & $\begin{array}{c}\boldsymbol{\sigma}_{\mathrm{m}}{ }^{2} \pm \mathbf{S E} \\
\text { Non-nesting }\end{array}$ \\
\hline F01 & 119 & $0.55 \pm 0.07$ & 13 & $0.15 \pm 0.04$ & 105 & $0.63 \pm 0.07$ \\
F02 & 82 & $0.35 \pm 0.06$ & - & - & 82 & $0.35 \pm 0.06$ \\
F03 & 124 & $1.62 \pm 0.21$ & 86 & $2.17 \pm 0.27$ & 37 & $0.14 \pm 0.07$ \\
F04 & 24 & $0.34 \pm 0.10$ & - & - & 24 & $0.34 \pm 0.10$ \\
F05 & 65 & $1.16 \pm 0.37$ & - & - & 65 & $1.16 \pm 0.37$ \\
F08 & 22 & $1.87 \pm 0.50$ & 22 & $1.88 \pm 0.50$ & - & - \\
F09 & 27 & $2.24 \pm 0.44$ & 27 & $2.24 \pm 0.44$ & - & - \\
\hline M01 & 105 & $8.34 \pm 0.91$ & 105 & $8.49 \pm 0.91$ & - & - \\
M02 & 36 & $0.90 \pm 0.19$ & 36 & $0.90 \pm 0.19$ & - & - \\
M03 & 95 & $7.77 \pm 0.77$ & 95 & $7.76 \pm 0.77$ & - & - \\
M04 & 214 & $2.21 \pm 0.22$ & 96 & $3.94 \pm 0.38$ & 117 & $0.36 \pm 0.04$ \\
M05 & 19 & $6.16 \pm 0.92$ & 19 & $5.89 \pm 1.02$ & - & - \\
\hline Females & $66 \pm 17$ & $1.16 \pm 0.29$ & $37 \pm 17$ & $1.61 \pm 0.49$ & $63 \pm 15$ & $0.52 \pm 0.18$ \\
Males & $94 \pm 34$ & $5.08 \pm 1.50$ & $70 \pm 18$ & $5.42 \pm 1.36$ & 117 & 0.36 \\
Total & $78 \pm 17$ & $2.79 \pm 0.84$ & $55 \pm 13$ & $3.73 \pm 1$ & $72 \pm 15$ & $0.5 \pm 0.15$ \\
\hline
\end{tabular}

$* \sigma_{\mathrm{m}}{ }^{2} \pm \mathrm{SE}$ : Motion variance \pm standard error 


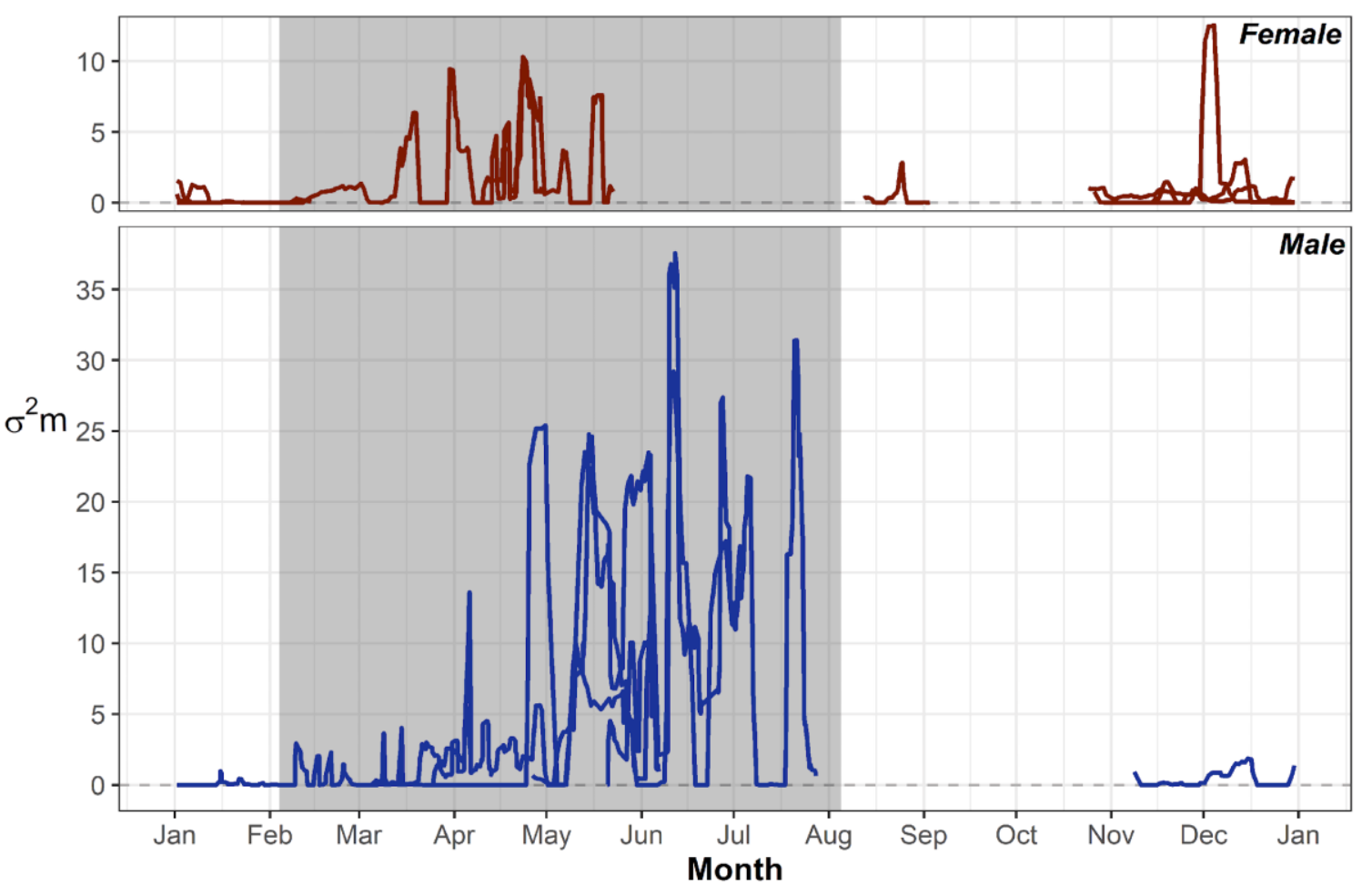

Fig. 3. Monthly motion variances for male and female radio-tracked $B$. cyanea, with the avian nesting season (4 February - 5 August) highlighted in grey.

Our Bayesian regression model lacked evidence of autocorrelation between the model variables: the autocorrelation parameters diminish to near zero by about 25 lags. The posterior predictive check plot (Fig. A.6) suggests that our simulated data do not perfectly replicate our observed data, thus reducing model fit. Our Bayesian regression model results (Fig. 4B) further support our observations from Fig. 4A, displaying the dispersion of motion variances during the nesting and non-nesting seasons, across males and females $\left(R^{2}=0.327\right)$. The coefficients for activity during the non-nesting season $(-0.5 \pm 0.15 ; 95 \% \mathrm{BCrl}:-0.35-0.25)$, and for males $(-0.11 \pm 0.33 ; 95 \% \mathrm{BCrl}:-0.79-0.54)$ were both negative, suggesting reduced activity. Males exhibited more individual variation in activity, compared to females -most likely because we only radiotracked one male during the non-nesting season. The large overlaps between coefficients suggest that season and sex are not the only factors affecting snake activity. 
A

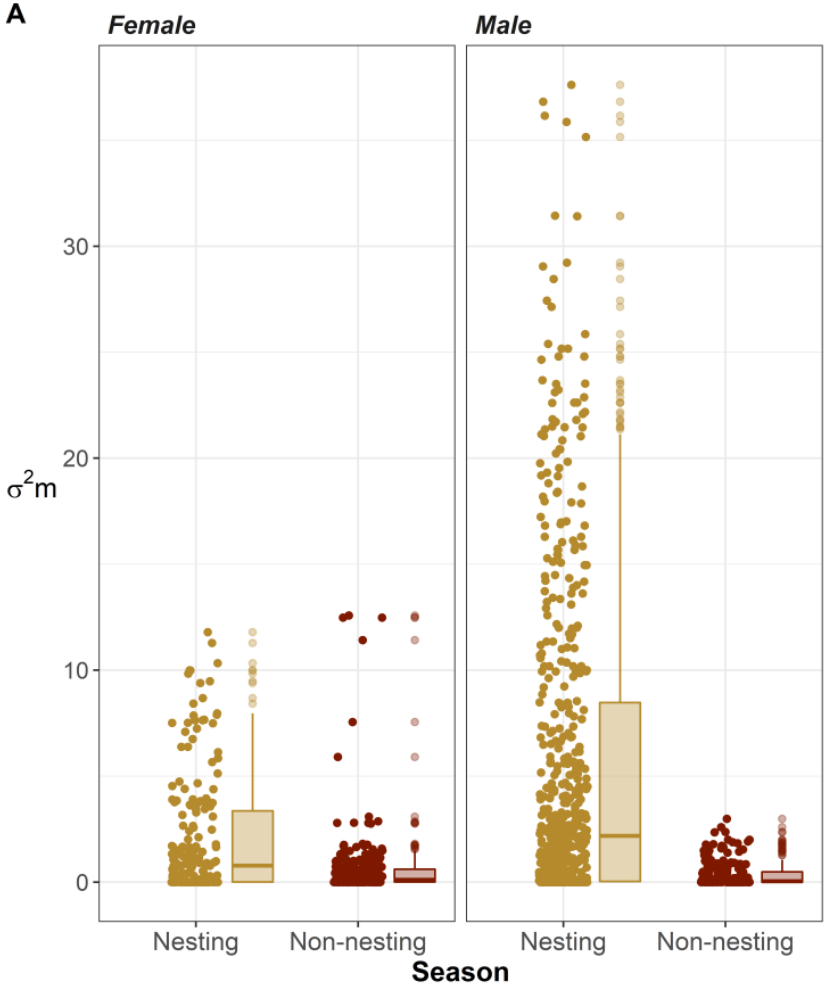

B

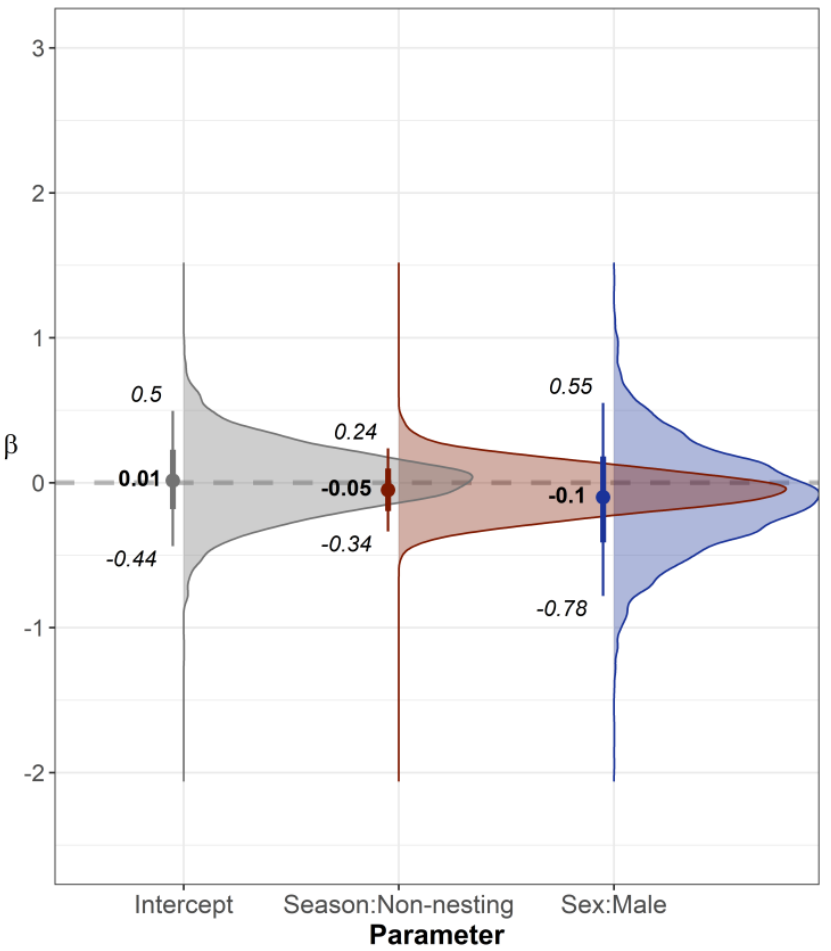

Fig. 4. Seasonal differences in motion variance between sexes. A) Box and jittered scatter plots of seasonal motion variance values split between female and male. B) Model averaging results with point estimates and $95 \% \mathrm{BCrl}$.

Boiga cyanea depredated avian nests primarily between April and July (Fig. 5). In 2018 and 2019, the nest monitoring cameras recorded fewer nest depredations by B. cyanea compared to previous years (Fig. A.5). We attempted to standardize nest depredations by $B$. cyanea accounting for trapping effort: we divided the total number of nests depredated each month by the total number of exposure days per month of the nest monitoring cameras. 


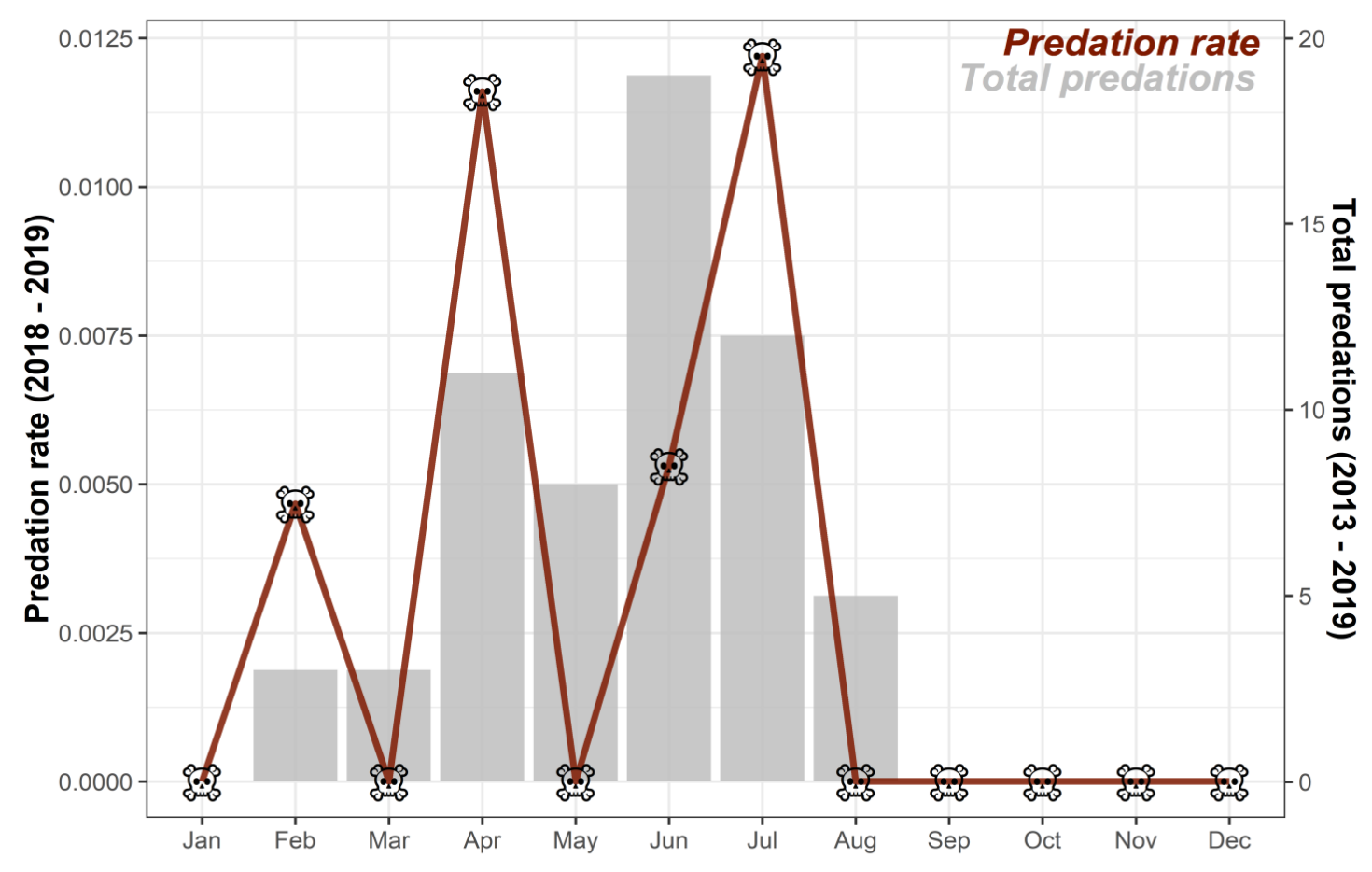

Fig. 5. Monthly avian nest depredation rates by B. cyanea during the 2018 and 2019 avian nesting seasons, and the total number of nest depredations by B. cyanea between 2013 and 2019. These data were obtained via the continuously monitoring nest cameras at SBR.

\subsubsection{Nocturnal activity}

If snakes had moved from their diurnal refugia by their first nocturnal fix, they generally continued moving throughout the night. We assessed nights with $\geq 2$ nocturnal fixes to gauge their activity patterns (Table A.4).

There is considerable temporal overlap ( $\Delta$ hat $=0.68$ ) between $B$. cyanea predation activity recorded by the nest monitoring cameras, and radio-tracked $B$. cyanea foraging activity. Predation activity is concentrated just after dark, while foraging activity appears consistent throughout the night. We observe three snake foraging activity peaks in Fig. 6 as a result of our tracking regime -three night-time fixes spaced apart by approximately four-hour intervals. 


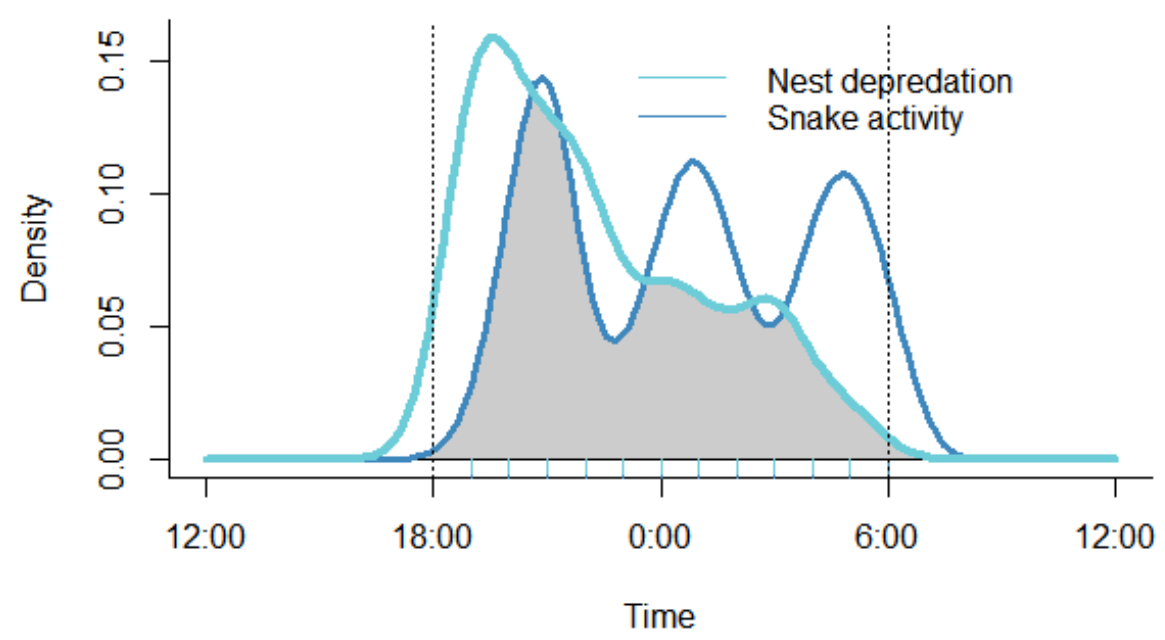

Fig. 6. Temporal activity density curves: B. cyanea activity (dark blue) and B. cyanea nest depredations (light blue). The overlap between the two curves is shaded in grey.

Our snakes generally travelled further at night during the avian nesting season $(n=300)$ compared to the non-nesting season ( $n=110$; Fig. 7). Movement and stationary behaviours were significantly different during the avian nesting and non-nesting seasons (Pearson's Chi-squared Test, $p$-value $=0.003$ ). Of the 300 nocturnal fixes recorded during the nesting season, snakes were moving $58 \%$ of time ( $n=174)$. Of the 110 nocturnal fixes during the non-nesting season, snakes were moving only $41 \%$ of the time $(n=45)$.

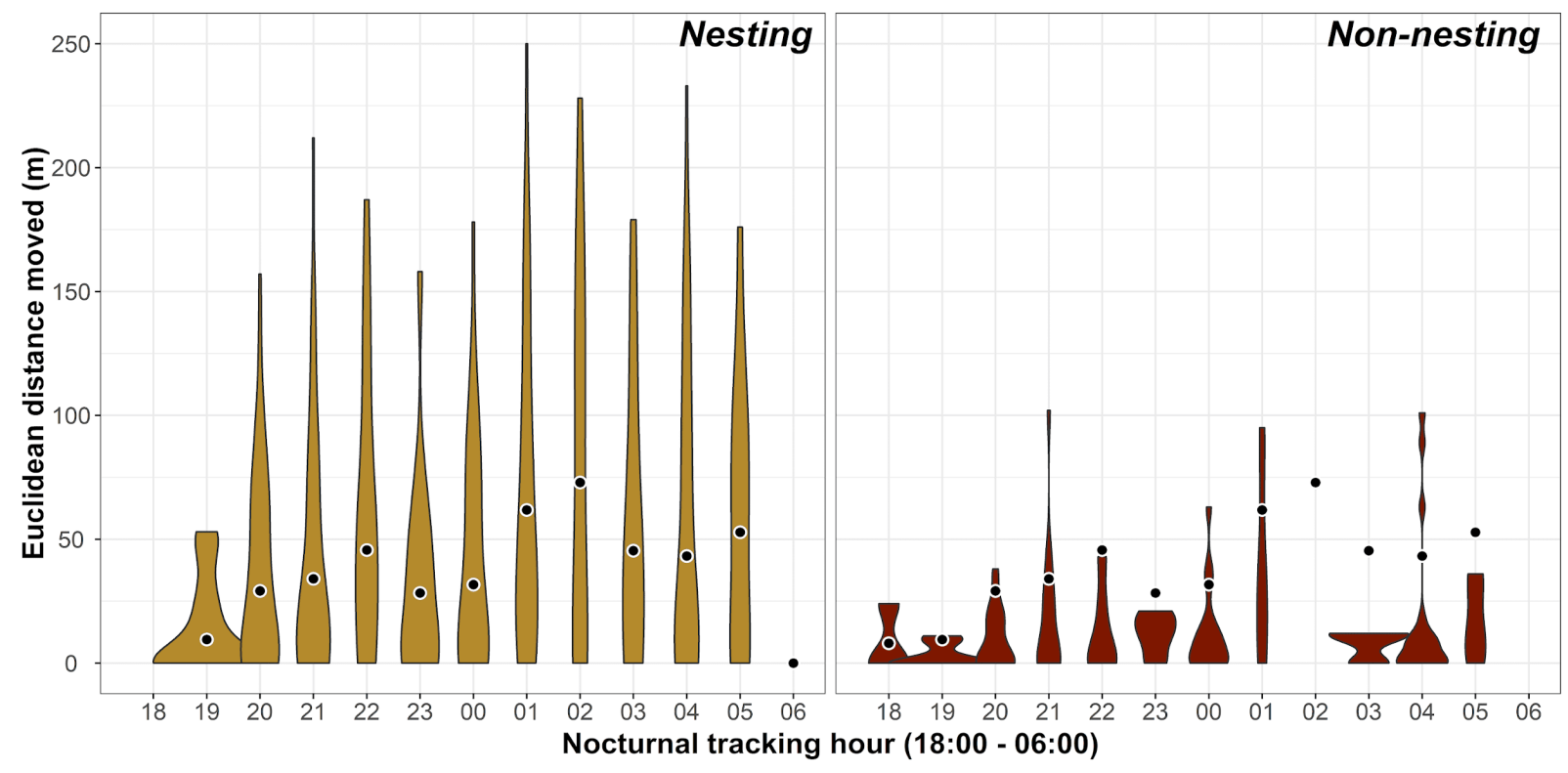

Fig. 7. Euclidean distances between snake locations at specific nocturnal hours and previous daytime refugia during the avian nesting season and the non-nesting season. The data illustrated are collected from individuals' radio-tracked between 2018.03.14 and 2018.09.03, and between 2019.01.15 and 2019.06.08. 


\section{DISCUSSION}

Male and female Boiga cyanea move and use space in different ways. Our males typically moved two and a half times farther and used areas five and a half times larger during the study. Our male and female $B$. cyanea differed in seasonal activity and space use. During the avian nesting season, radio-tracked B. cyanea were approximately seven times more active -moving farther and more frequently (matching our prediction of increased activity during the nesting season). The snakes also used areas six times larger during the avian nesting season compared to the non-nesting season (contrary to our prediction of increased space use during the non-nesting season). Our observations suggest that $B$. cyanea are strictly nocturnal foragers, actively foraging throughout the night. Additionally, our B. cyanea typically sheltered at heights above $2 \mathrm{~m}$, and descended closer to the ground to forage at night.

The nesting season -from February to August, partially overlaps with the wet season at the Sakaerat Biosphere Reserve (SBR). The wet season spans from May to October, with typical peaks in May and in September, and low rainfall between June and August. Khamcha et al. (2018) reported that rainfall and nest depredations by B. cyanea were positively correlated, speculating increased snake activity connected the two. The wet season might trigger a general increase in invertebrate and herpetofauna activity, thereby affecting their interactions with higher trophic levels (Illera and Díaz, 2006; Saenz et al., 2006). With greater prey activity comes greater prey encounter probability. Multiple biotic (e.g. life stage, body condition, prey presence, etc.; Horesh et al., 2017; Kotler et al., 1992) and abiotic factors (e.g. moonlight, temperature, rainfall, etc.; Campbell et al., 2009; Eskew and Todd, 2017) acting synergistically might be driving the increase in B. cyanea activity during the avian nesting season. In contrast, Tobin et al. (1999) reported that B. irregularis on Guam did not exhibit any difference in distances travelled across the rainy and dry seasons. However, Guam as a small island system may have limited seasonal fluctuations in temperature, although situated at similar latitudes to our site. The invasive nature of the snake may inhibit seasonal behaviours, or the system may simply lack seasonal prey availability fluctuations.

Throughout our study, we detected no movement behaviour during daylight hours. Despite non-systematic sampling of diurnal snake behaviour, it appears that $B$. cyanea are active primarily at night. Bulian and Bannasan (1999) report similar ad-hoc observations on B. cyanea diel activity, but have observed B. cyanea copulating on multiple occasions during the early daylight hours -around 0700 hours. We observed no mating behaviour during our study. Only on one occasion we located our male and female B. cyanea in the same tree during daylight hours; this could suggest they were possibly copulating but we have no visual evidence of the event. The nest monitoring cameras detected no daytime avian nest depredations from $B$. cyanea further supporting our suspicions of exclusively nocturnal activities (Khamcha et al., 2018).

The tracked individuals often began activity just after sunset, at dusk, and ceased at dawn, just before sunrise. Similar observations exist regarding Boiga irregularis nocturnal activity on Guam, with snakes becoming active around sunset, and remaining more or less so throughout the night until ceasing their activity around sunrise (Fritts and Chiszar, 1999; Lardner et al., 2014; Siers et al., 2018). A further similarity with $B$. irregularis may suggest that the stationary periods we observed are the result of prey digestion. On Guam supplementary fed snakes showed lowered activity for 1 to 5 days post feeding (Siers et al., 2018), broadly reflecting our mean stationary period of $3.29 \pm 0.66$ days.

The snakes were likely to move throughout the night if we recorded moving behaviour by 4 hours post sunset. Thus, we suggest $B$. cyanea are primarily active foragers that might also ambush prey on occasion similar to their invasive congener on Guam, who exhibit a combination of the two foraging modes (Rodda, 
1992). We failed to detect any avian nest depredations by radio-telemetered individuals during our study. However, our tracking regime could have allowed our snakes to depredate avian nests during inter-night and intra-night tracking intervals. Low encounter rates of avian nests, active selection of prey sizes, and gape limitations may be reasons why we detected no nest predations during our study (Shine, 1991). Being predominantly active foragers and generalists, B. cyanea may still be feeding frequently on other prey (Beaupre and Montgomery, 2007), as SBR hosts a high diversity of sedentary and active prey species (Crane et al., 2018). Our individuals likely fed on smaller but more widespread and abundant prey items, like forest lizards (Calotes sp.), geckos or frogs (Bulian and Bannasan, 1999) although frogs in the SBR dry evergreen forest are seasonally restricted to areas adjacent to water.

The nest monitoring cameras detected higher numbers of avian nest depredations during the early hours after sunset, at around 1900 hours. The ornithological researchers observed B. cyanea -presumably the same individual, depredating single nest contents from the same nest on consecutive nights, until all the eggs and fledglings were depredated (Personal comm., Angkaew 2017). During these occasions, the predator was likely to have selected refugia relatively close to the avian nests to optimize its feeding benefits while reducing its predation risk. From our radio-tracking data on distances travelled by 1900 hours, 'relatively close' would translate to an average distance of $26.2 \pm 4.93 \mathrm{~m}$, and a maximum of $53 \mathrm{~m}$. Fledglings and avian eggs might be efficient prey items for $B$. cyanea: the time taken to subdue and ingest these prey might be greatly reduced compared to larger and effectively defensive prey (Pleguezuelos et al., 2007), thus reducing the predator's own predation risk (Mullin and Cooper, 1998).

The tracked snakes sheltered at heights over $2 \mathrm{~m}$ off the ground during most diurnal fixes ( $\approx 95 \%)$. Thus $B$. cyanea must frequently descend from their diurnal refugia to lower heights at night to forage. Our findings are consistent with descriptions of the Dark-headed cat snake Boiga nigriceps (Fujishima et al., 2021) and $B$. irregularis (Rodda, 1992) foraging heights. The nest predation records show that White-rumped Shamas Kittacincla malabarica (WRSH), Abbott's babbler Malacocincla abbotti (ABBA), and Scaly-crowned Babblers Malacopteron cinereum (SCBA) were the three most depredated species' nests by $B$. cyanea at SBR. Khamcha and Gale (2020) report $B$. cyanea being responsible for $\approx 27 \%$ of predations by top-five predators on WRSH, $\approx 25 \%$ on ABBA, and $\approx 19 \%$ on SCBA. The average nest height for WRSH is around $1.6 \mathrm{~m}$ (Khamcha and Gale, 2020), that for ABBA is $0.7 \mathrm{~m}$ (Khamcha and Gale, 2020), and that for SCBA is $0.98 \mathrm{~m}$ (Somsiri et al., 2020) -similar to the median movement height (1.5 m; IQR: 3.5) recorded for our B. cyanea. Boiga cyanea might forage closer to the ground, especially during the avian nesting season, to actively hunt for ground and understory nesting bird nests.

Our study is the first to explore the space use and activity patterns of a regionally important snake predator in relation to its prey. We attempted to quantify $B$. cyanea foraging activity by implicitly assuming their movements, particularly during the avian nesting season, were related to foraging rather than other biological functions. For this reason, our findings regarding $B$. cyanea foraging behaviour must not be overstated. We developed our nocturnal tracking protocol to minimize our influence on the snakes' natural behaviours; locating each individual every night, rather than alternate nights, would have provided more detailed insights into their nocturnal activity patterns while potentially revealing movement patterns occurring at different temporal scales. The disparity in total fixes between the avian nesting and nonnesting seasons hindered us from making robust statistical inferences on seasonal horizontal and vertical movements. Having no radio-tracking overlap across the seasons for most individuals $(n=9)$ further limits our inferences on seasonal changes in activity patterns. 
We caution against extrapolating seasonal space use and activity patterns of males and females, because of possible sources of sampling biases, as detailed in the STRANGE framework (Webster and Rutz, 2020). Social background: individuals' size might have influenced their movements with respect to their conspecifics, either through avoidance or attraction behaviour. Trappability and self-selection: individuals predisposed to moving towards anthropogenic habitat features may have been more likely to be captured. Because most individuals were captured opportunistically $(n=9)$, our sample is non-random and nonrepresentative of the $B$. cyanea population at large. Acclimation and habituation: our presence during nighttime fixes likely caused behavioural changes despite our efforts to minimize disturbance. Natural changes in responsiveness: the avian nesting seasons in 2018 and 2019 witnessed lower nest depredations by $B$. cyanea compared to 2013 - 2017. Reasons for the two anomalous years are unknown. The association between B. cyanea activity and nest depredations during our study period, might therefore not reflect that of previous years, or of those to come.

Our study highlights the need to explore $B$. cyanea diet to quantify what proportion fledglings and avian eggs constitute at SBR. Studying patterns of prey selection (whether active or opportunistic) and understanding how $B$. cyanea locate avian nests could help better elucidate these complex predator-prey relationships. Bird populations at SBR face significant predation pressure from both nocturnal snakes and the Northern Pig-tailed Macaque Macaca leonina (Kaisin et al., 2018; Khamcha et al., 2018). Understanding the combined effect of these major sympatric predators on nest survival could help develop strategies to increase nest success. The results of this study might be applicable to other parts of Southeast Asia where snakes might be important avian nest predators, especially of bird populations of conservation concern (e.g. Donald et al., 2009). 


\section{DECLARATION OF COMPETING INTEREST}

The authors declare that they have no known competing financial interests or personal relationships that could have appeared to influence the work reported in this paper.

\section{ACKNOWLEDGEMENTS}

We sincerely thank the National Science and Technology Development Agency of Thailand (NSTDA) for funding this research project (grant number: P-17-50476). We thank the National Research Council of Thailand (NRCT) for issuing our research permit (Number: 0002/4493). We thank the Institute of Animals for Scientific Purpose Development (IAD) for issuing our animal use license (Number: 1-08385-2562). We thank the Thailand Institute of Scientific and Technological Research for granting permission to conduct research within the Sakaerat Biosphere Reserve (SBR). We sincerely thank the Sakaerat Environmental Research Station (SERS) for logistic support throughout the duration of the project. We thank the Suranaree University of Technology for bureaucratic assistance. We thank Nakhon Ratchasima zoo, in particular D.V.M. Wirongrong Changphet, for providing veterinary expertise. We thank all fellow researchers, interns and staff at SERS for their contributions towards the running of this project. Lastly, a very special thanks to field technicians Nathaniel Quarrell, Jizel Miles, Thomas Prewett, Rose Stroup and Harry Ward-Smith for their time, devotion, enthusiasm, hard work and work ethic.

Funding: This work was supported by the National Science and Technology Development Agency of Thailand (grant number: P-17-50476, 2017).

\section{AUTHOR CONTRIBUTIONS}

Conceptualization: A.D., C.T.S., G.G., and D. K.; Methodology: A.D., C.T.S., G.G., and B.M.M.; Formal Analysis: A.D. and B.M.M.; Investigation: A.D.; Resources: A.D., C.T.S., G.G., D. K., and S.W.; Writing Original Draft: A.D. and C.T.S.; Writing - Review \& Editing: A.D., C.T.S., G.G., B.M.M., D. K., and S.W.; Visualization: A.D. and B.M.M.; Supervision: C.T.S., G.G., and S.W.; Funding Acquisition: A.D., C.T.S., G.G., D. K., and S.W. The author(s) read and approved the final manuscript. 


\section{APPENDIX A.}

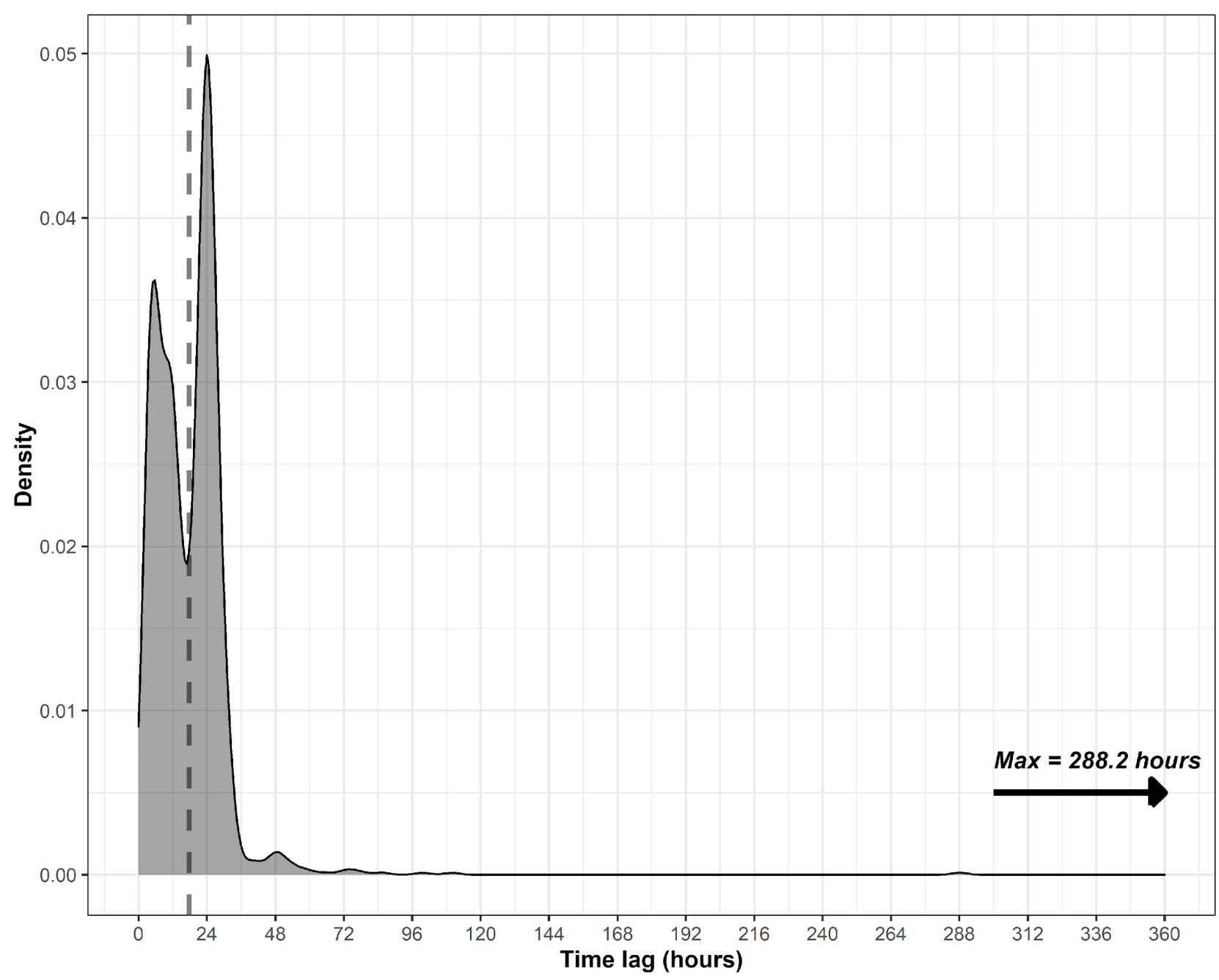

Fig. A.1. Average tracking interval ( $17.63 \pm 0.37$ hours) between diurnal and nocturnal fixes of our radiotracked individuals. The peak around 48 hours is likely the result of times we were unable to detect radiosignal on our individuals. The peaks between 72 hours and 288 hours are primarily the result of snakes were awaiting transmitter replacement surgery at the research facility. 


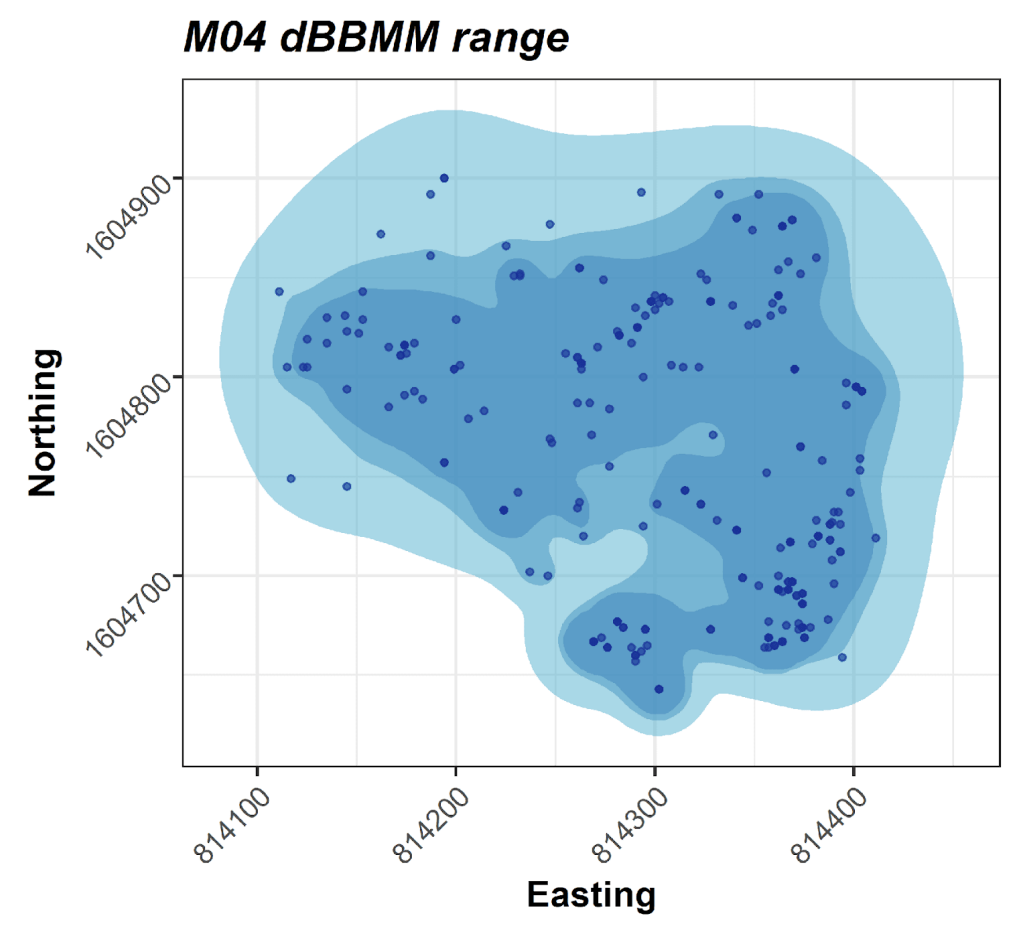

Fig. A.2. 99\%, 95\%, and 90\% dBBMM isopleth contours M04, radio-tracked 6 November 2018 and 8 June 2019. 


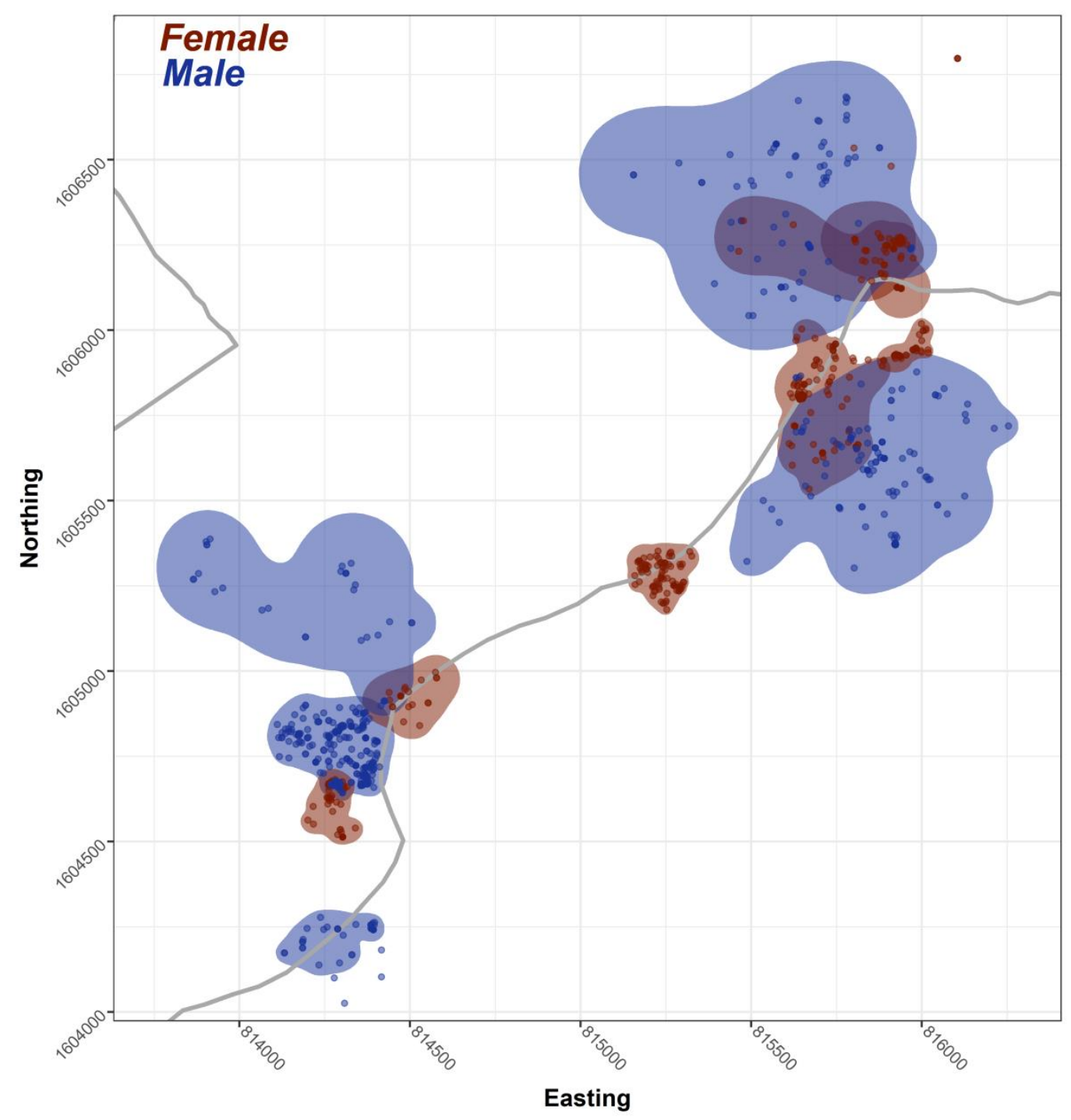

Fig. A.3. DBBMM occurrence distributions illustrating $99 \%$ isopleth contours for male (blue) and female (red) radio-tracked B. cyanea between 21 October 2017 and 8 June 2019 in reference to the main roads (grey) within the SBR core area. 


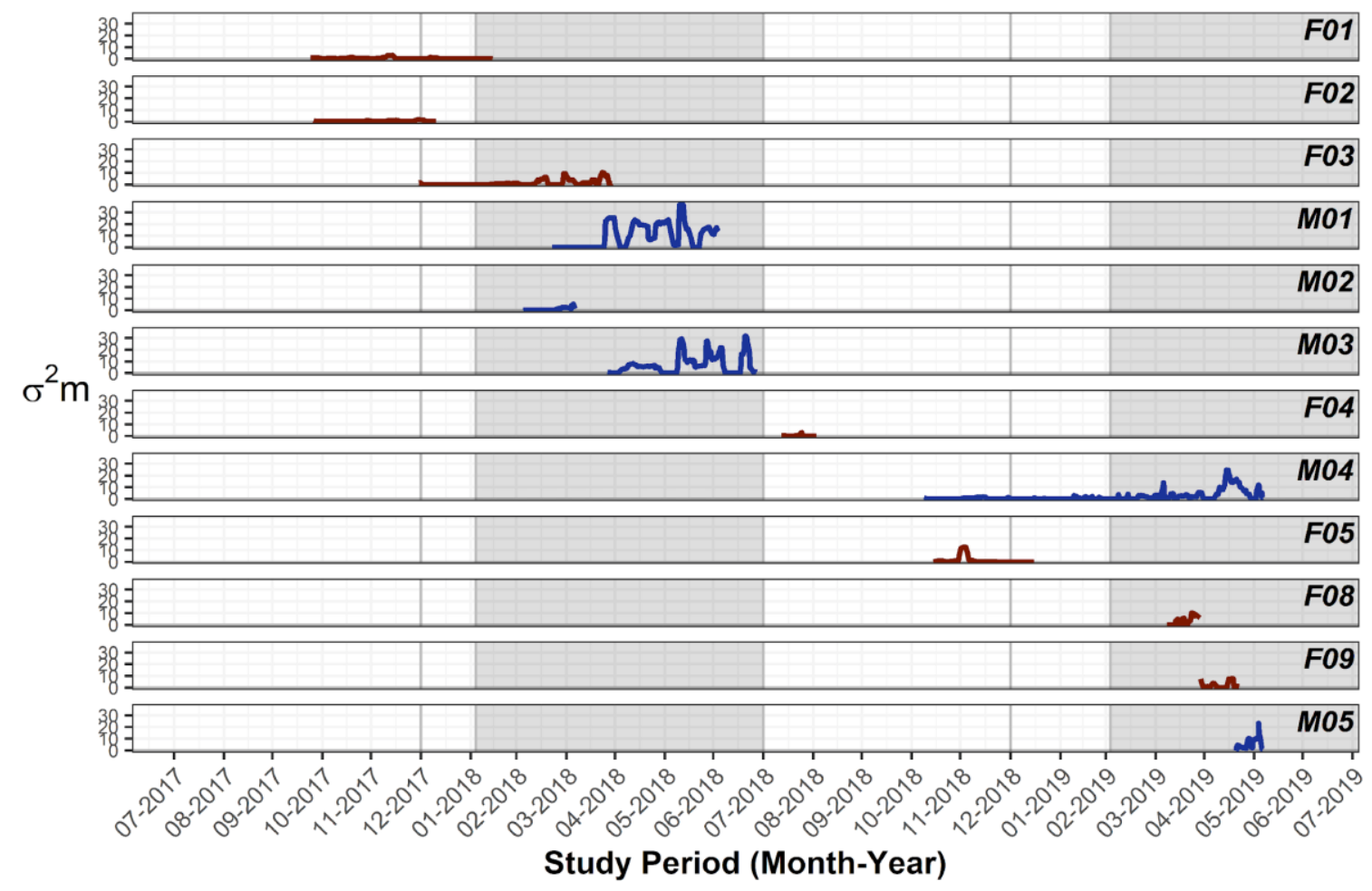

Fig. A.4. Individual motion variances for radio-tracked B. cyanea with nesting seasons 2018 and 2019 evidenced in grey. 


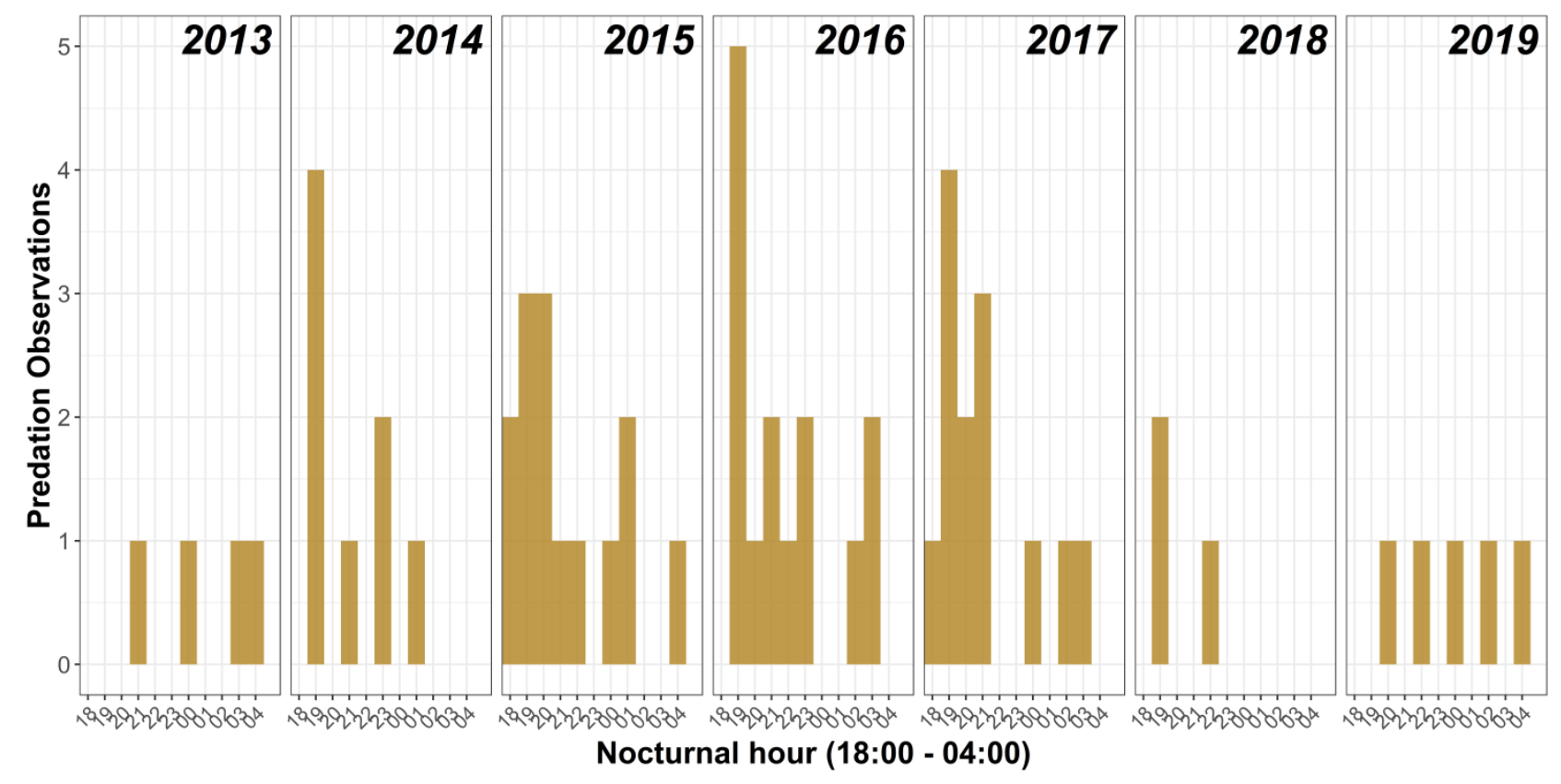

Fig. A.5. Avian nest depredations by B. cyanea broken down by hour and by year, recorded via the continuously monitoring nest cameras at SBR. 


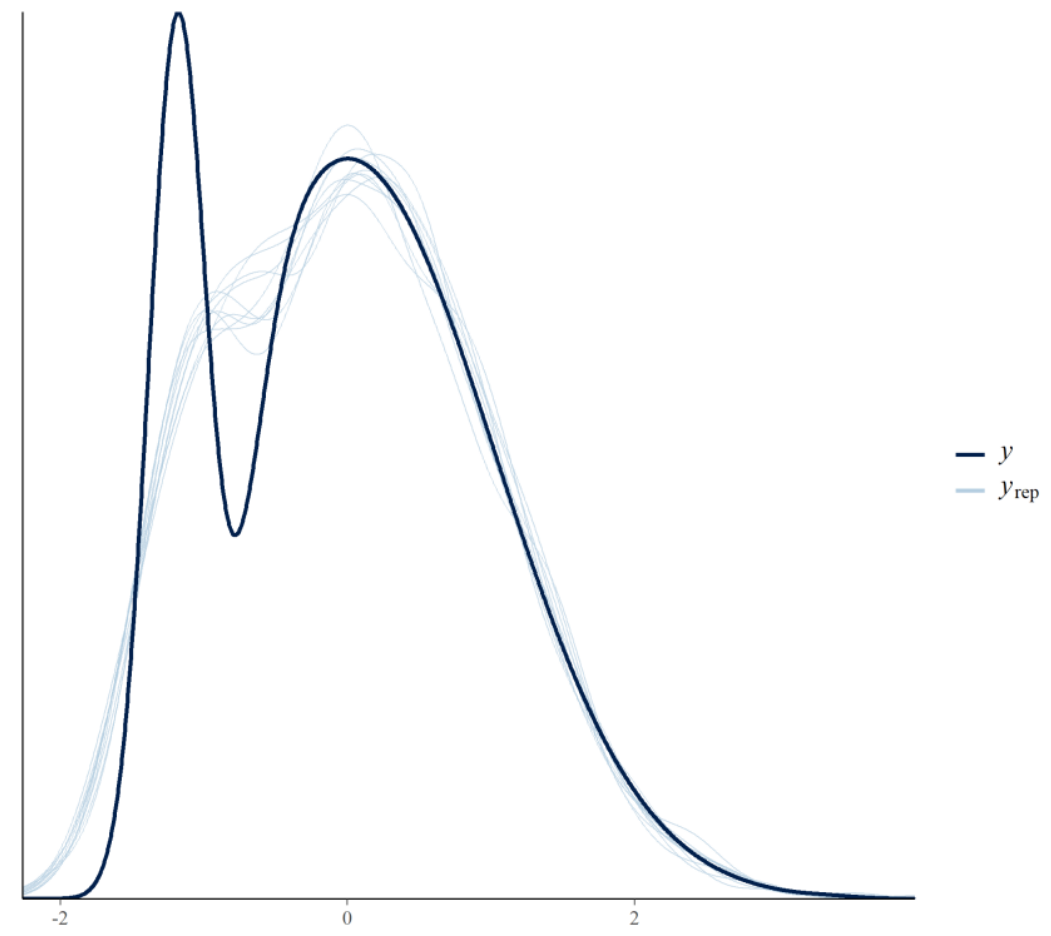

Fig. A.6. Posterior predictive check for Bayesian regression model plotting observed data (y) and simulated data $\left(\mathrm{y}_{\text {rep }}\right)$. 
Table A.1. Occurrence distributions and motion variances of radio-tracked Boiga cyanea between 21 October 2017 and 8 June 2019 using window size 11 and margin size 5.

\begin{tabular}{|c|c|c|c|c|c|}
\hline $\begin{array}{c}\text { Snake } \\
\text { ID }\end{array}$ & $\begin{array}{c}\text { Days } \\
\text { Tracked }\end{array}$ & $\begin{array}{c}90 \% \text { dBBMM } \\
\text { (ha) }\end{array}$ & $\begin{array}{c}95 \% \\
\text { dBBMM } \\
\text { (ha) }\end{array}$ & $\begin{array}{c}\text { 99\% dBBMM } \\
\text { (ha) }\end{array}$ & $\sigma_{m}^{2} \pm S E$ \\
\hline F01 & 119 & 1.63 & 2.10 & 3.11 & $0.53 \pm 0.06$ \\
\hline F02 & 82 & 0.98 & 1.53 & 2.64 & $0.37 \pm 0.05$ \\
\hline F03 & 124 & 4.17 & 6.40 & 11.25 & $1.52 \pm 0.19$ \\
\hline F04 & 24 & 0.56 & 0.82 & 1.38 & $0.34 \pm 0.1$ \\
\hline F05 & 65 & 1.58 & 4.88 & 12.53 & $1.27 \pm 0.35$ \\
\hline F08 & 22 & 2.24 & 3.26 & 5.72 & $1.33 \pm 0.37$ \\
\hline F09 & 27 & 1.88 & 2.70 & 4.72 & $2.23 \pm 0.45$ \\
\hline M01 & 105 & 28.13 & 37.54 & 57.78 & $8.59 \pm 0.91$ \\
\hline M02 & 36 & 1.90 & 2.73 & 4.06 & $0.66 \pm 0.14$ \\
\hline M03 & 95 & 18.43 & 24.88 & 39.89 & $8.02 \pm 0.78$ \\
\hline M04 & 214 & 3.93 & 5.21 & 8.58 & $2.17 \pm 0.21$ \\
\hline M05 & 19 & 16.70 & 21.08 & 30.61 & $7.44 \pm 1$ \\
\hline
\end{tabular}

*dBBMM: Dynamic Brownian bridge movement model estimate; ${ }^{*} \sigma_{\mathrm{m}}{ }^{2} \pm \mathrm{SE}$ : Motion variance and standard error. 
Table A.2. Occurrence distributions and motion variances of radio-tracked Boiga cyanea between 21 October 2017 and 8 June 2019 using window size 15 and margin size 7.

\begin{tabular}{|c|c|c|c|c|c|}
\hline $\begin{array}{c}\text { Snake } \\
\text { ID }\end{array}$ & $\begin{array}{c}\text { Days } \\
\text { Tracked }\end{array}$ & $\begin{array}{c}90 \% \text { dBBMM } \\
\text { (ha) }\end{array}$ & $\begin{array}{c}95 \% \\
\text { dBBMM } \\
\text { (ha) }\end{array}$ & $\begin{array}{c}\text { 99\% dBBMM } \\
\text { (ha) }\end{array}$ & $\sigma_{m}^{2} \pm S E$ \\
\hline F01 & 119 & 1.70 & 2.17 & 3.15 & $0.5 \pm 0.05$ \\
\hline F02 & 82 & 0.99 & 1.48 & 2.45 & $0.35 \pm 0.05$ \\
\hline F03 & 124 & 3.86 & 5.89 & 10.27 & $1.64 \pm 0.21$ \\
\hline F04 & 24 & 0.53 & 0.77 & 1.29 & $0.32 \pm 0.09$ \\
\hline F05 & 65 & 2.19 & 5.53 & 12.68 & $1.33 \pm 0.33$ \\
\hline F08 & 22 & 1.88 & 2.60 & 4.26 & $1.31 \pm 0.23$ \\
\hline F09 & 27 & 1.81 & 2.52 & 4.19 & $2.11 \pm 0.41$ \\
\hline M01 & 105 & 27.68 & 36.31 & 54.35 & $8.37 \pm 0.81$ \\
\hline M02 & 36 & 1.80 & 2.67 & 4.16 & $0.69 \pm 0.16$ \\
\hline M03 & 95 & 18.70 & 25.06 & 39.66 & $8.11 \pm 0.67$ \\
\hline M04 & 214 & 4.01 & 5.27 & 8.57 & $2.08 \pm 0.19$ \\
\hline M05 & 19 & 11.86 & 15.34 & 22.92 & $7.85 \pm 0.88$ \\
\hline
\end{tabular}

*dBBMM: Dynamic Brownian bridge movement model estimate; ${ }^{*} \boldsymbol{\sigma}_{\mathrm{m}}{ }^{2} \pm \mathrm{SE}$ : Motion variance and standard error. 
Table A.3. Occurrence distributions and motion variances of radio-tracked Boiga cyanea between 21 October 2017 and 8 June 2019 using window size 21 and margin size 9.

\begin{tabular}{|c|c|c|c|c|c|}
\hline $\begin{array}{c}\text { Snake } \\
\text { ID }\end{array}$ & $\begin{array}{c}\text { Days } \\
\text { Tracked }\end{array}$ & $\begin{array}{c}90 \% \text { dBBMM } \\
\text { (ha) }\end{array}$ & $\begin{array}{c}95 \% \\
\text { dBBMM } \\
\text { (ha) }\end{array}$ & $\begin{array}{c}\text { 99\% dBBMM } \\
\text { (ha) }\end{array}$ & $\sigma_{m}^{2} \pm S E$ \\
\hline F01 & 119 & 1.79 & 2.26 & 3.25 & $0.5 \pm 0.04$ \\
\hline F02 & 82 & 0.86 & 1.34 & 2.32 & $0.36 \pm 0.04$ \\
\hline F03 & 124 & 3.77 & 5.56 & 9.24 & $1.51 \pm 0.15$ \\
\hline F04 & 24 & 0.65 & 0.87 & 1.35 & $0.42 \pm 0.09$ \\
\hline F05 & 65 & 2.82 & 6.24 & 12.76 & $1.57 \pm 0.33$ \\
\hline F08 & 22 & 2.12 & 2.90 & 4.70 & $1.77 \pm 0.26$ \\
\hline F09 & 27 & 1.76 & 2.41 & 3.88 & $1.88 \pm 0.36$ \\
\hline M01 & 105 & 27.23 & 35.39 & 51.96 & $8.02 \pm 0.7$ \\
\hline M02 & 36 & 1.63 & 2.53 & 4.03 & $0.97 \pm 0.29$ \\
\hline M03 & 95 & 18.67 & 25.08 & 39.34 & $7.62 \pm 0.61$ \\
\hline M04 & 214 & 4.12 & 5.39 & 8.60 & $2.17 \pm 0.19$ \\
\hline M05 & 19 & 5.67 & 7.37 & 11.38 & $6.47 \pm 0.59$ \\
\hline
\end{tabular}

*dBBMM: Dynamic Brownian bridge movement model estimate; ${ }^{*} \boldsymbol{\sigma}_{\mathrm{m}}{ }^{2} \pm \mathrm{SE}$ : Motion variance and standard error. 
Table A.4. Tracking interval summaries of nights with $\geq 2$ nocturnal fixes, during which the snakes had moved or were observed moving.

\begin{tabular}{cccc}
\hline Nocturnal fix & Fixes & Moved & Moving \\
\hline $1^{\text {st }}$ interval (18:00-21:59) & $110(35 \%)$ & $66(34 \%)$ & $62(37 \%)$ \\
$2^{\text {nd }}$ interval (22:00-01:59) & $97(31 \%)$ & $64(33 \%)$ & $58(35 \%)$ \\
$3^{\text {rd }}$ interval (02:00-07:00) & $105(34 \%)$ & $66(34 \%)$ & $47(28 \%)$ \\
\hline Total & 312 & $196(63 \%)$ & $197(54 \%)$ \\
\hline
\end{tabular}




\section{REFERENCES}

Amelon, S.K., Dalton, D.C., Millspaugh, J.J., Wolf, S.A., 2009. Radiotelemetry: techniques and analysis. In: Kunz, T. H.; Parsons, S. eds. Ecological and behavioral methods for the study of bats. Johns Hopkins University Press, Baltimore, pp. 57-77.

Angkaew, R., Sankamethawee, W., Pierce, A.J., Savini, T., Gale, G.A., 2019. Nesting near road edges improves nest success and post-fledging survival of White-rumped Shamas (Copsychus malabaricus) in northeastern Thailand. The Condor 121, 1-15. https://doi.org/10.1093/condor/duy013

Beaupre, S., Montgomery, C.E., 2007. The meaning and consequences of foraging mode in snakes, in: Lizard Ecology: The Evolutionary Consequences of Foraging Mode. pp. 334-367. https://doi.org/10.1017/СВO9780511752438.013

Bivand, R., Rundel, C., Pebesma, E., Stuetz, R., Hufthammer, K.O., Giraudoux, P., Davis, M., Santilli, S., 2020. rgeos: Interface to Geometry Engine - Open Source ('GEOS').

Boback, S.M., Nafus, M.G., Yackel Adams, A.A., Reed, R.N., 2020. Use of visual surveys and radiotelemetry reveals sources of detection bias for a cryptic snake at low densities. Ecosphere 11. https://doi.org/10.1002/ecs2.3000

Bracis, C., Bildstein, K.L., Mueller, T., 2018. Revisitation analysis uncovers spatio-temporal patterns in animal movement data. Ecography 41, 1801-1811. https://doi.org/10.1111/ecog.03618

Bulian, J., Bannasan, T.T.A., 1999. Observations on Boiga cyanea. Litteratura Serpentium 19, 175-183.

Bürkner, P.-C., 2017. brms: An R Package for Bayesian Multilevel Models Using Stan. Journal of Statistical Software 80, 1-28. https://doi.org/10.18637/jss.v080.i01

Calenge, C., 2006. The package adehabitat for the R software: tool for the analysis of space and habitat use by animals. Ecological Modelling 197, 1035.

Campbell, S., Mackessy, S., Clarke, J., 2009. Microhabitat Use by Brown Treesnakes (Boiga irregularis): Effects of Moonlight and Prey. Journal of Herpetology 42, 246-250. https://doi.org/10.1670/070681.1

Chan-ard, T., Parr, J., Nabhitabhata, J., 2015. A Field Guide to the Reptiles of Thailand. Oxford University Press, Oxford, New York.

Conry, P.J., 1988. High Nest Predation by Brown Tree Snakes on Guam. The Condor 90, 478-482. https://doi.org/10.2307/1368576

Cox, M., Van Dijk, P., Nabhitabhata, J., Thirakhupt, K., 1998. A photographic guide to snakes and other reptiles of Thailand and Southeast Asia [WWW Document]. URL https://www.car.chula.ac.th/display7.php?bib=b1834730 (accessed 11.29.20).

Crane, M., Silva, I., Marshall, B.M., Strine, C.T., 2020. Lots of movement, little progress: A review of reptile home range literature. bioRxiv 2020.12.03.409292. https://doi.org/10.1101/2020.12.03.409292

Crane, M., Strine, C., Knierim, T., Artchawakom, T., Suwanwaree, P., 2018. Herpetofaunal Species abundance, richness, and diversity in a dry tropical forest and agricultural Matrix at the Sakaerat biosphere reserve, Thailand. Herpetological Conservation and Biology 13, 586. 
Croston, R., Ackerman, J., Herzog, M., Kohl, J., Hartman, A., Peterson, S., Overton, C., Feldheim, C., Casazza, M., 2018. Duck nest depredation, predator behavior, and female response using video. The Journal of Wildlife Management 82. https://doi.org/10.1002/jwmg.21444

DeGregorio, B.A., Chiavacci, S.J., Benson, T.J., Sperry, J.H., Weatherhead, P.J., 2016a. Nest Predators of North American Birds: Continental Patterns and Implications. BioScience 66, 655-665. https://doi.org/10.1093/biosci/biw071

DeGregorio, B.A., Chiavacci, S.J., Weatherhead, P.J., Willson, J.D., Benson, T.J., Sperry, J.H., 2014. Snake predation on North American bird nests: culprits, patterns and future directions. Journal of Avian Biology 45, 325-333. https://doi.org/10.1111/jav.00364

DeGregorio, B.A., Weatherhead, P.J., Sperry, J.H., 2016b. Ecology and predation behaviour of Corn snakes (Pantherophis guttatus) on avian nests. Herpetological Conservation and Biology 11, 150-159.

DeGregorio, B.A., Weatherhead, P.J., Ward, M.P., Sperry, J.H., 2016c. Do seasonal patterns of rat snake (Pantherophis obsoletus) and black racer (Coluber constrictor) activity predict avian nest predation? Ecol Evol 6, 2034-2043. https://doi.org/10.1002/ece3.1992

Donald, P.F., Aratrakorn, S., Win Htun, T., Eames, J.C., Hla, H., Thunhikorn, S., Sribua-Rod, K., Tinun, P., Aung, S.M., Zaw, S.M., Buchanan, G.M., 2009. Population, distribution, habitat use and breeding of Gurney's Pitta Pitta gurneyi in Myanmar and Thailand. Bird Conservation International 19, 353-366. https://doi.org/10.1017/S0959270909008612

Dunnington, D., Thorne, B., 2020. ggspatial: Spatial Data Framework for ggplot2.

Eskew, E.A., Todd, B.D., 2017. Too Cold, Too Wet, Too Bright, or Just Right? Environmental Predictors of Snake Movement and Activity. cope 105, 584-591. https://doi.org/10.1643/CH-16-513

Fritts, T.H., Chiszar, D., 1999. Snakes on Electrical Transmission Lines: Patterns, Causes, and Strategies for Reducing Electrical Outages Due to Snakes, Problem Snake Management: the Habu and the Brown Treesnake. Cornell University Press. https://doi.org/10.7591/9781501737688-009

Fritts, T.H., Rodda, G.H., 1998. The role of introduced species in the degredation of island ecosystems: A Case History of Guam. Annu. Rev. Ecol. Syst. 29, 113-140. https://doi.org/10.1146/annurev.ecolsys.29.1.113

Fujishima, K., Tomonori, K., Kojima, Y., Hossman, M., Nishikawa, K., 2021. Short-term movements of Boiga nigriceps (Günther, 1863) with notes on its diet (Squamata: Colubridae). Herpetology Notes 14, 8389.

Gabry, J., Mahr, T., 2020. bayesplot: Plotting for Bayesian Models.

Gelman, A., Rubin, D.B., 1992. Inference from Iterative Simulation Using Multiple Sequences. Statist. Sci. 7, 457-472. https://doi.org/10.1214/ss/1177011136

Gelman, A., Su, Y.-S., Yajima, M., Hill, J., Pittau, M.G., Kerman, J., Zheng, T., Dorie, V., 2020. arm: Data Analysis Using Regression and Multilevel/Hierarchical Models.

Grolemund, G., Wickham, H., 2011. Dates and Times Made Easy with lubridate. Journal of Statistical Software 40, 1-25. https://doi.org/10.18637/jss.v040.i03

Harris, A., 2012. astroFns: Astronomy: time and position functions, misc. utilities. 
Harry W. Greene, 1997. Snakes: The Evolution of Mystery in Nature [WWW Document]. URL https://books.google.co.th/books/about/Snakes.html?id=io1TYkFAur8C\&redir_esc=y (accessed 11.29.20).

Hijmans, R.J., Etten, J. van, Sumner, M., Cheng, J., Baston, D., Bevan, A., Bivand, R., Busetto, L., Canty, M., Fasoli, B., Forrest, D., Ghosh, A., Golicher, D., Gray, J., Greenberg, J.A., Hiemstra, P., Hingee, K., Geosciences, I. for M.A., Karney, C., Mattiuzzi, M., Mosher, S., Nowosad, J., Pebesma, E., Lamigueiro, O.P., Racine, E.B., Rowlingson, B., Shortridge, A., Venables, B., Wueest, R., 2020. raster: Geographic Data Analysis and Modeling.

Horesh, S.J.A., Sivan, J., Rosenstrauch, A., Tesler, I., Degen, A.A., Kam, M., 2017. Seasonal biotic and abiotic factors affecting hunting strategy in free-living Saharan sand vipers, Cerastes vipera. Behavioural processes.

Illera, J.C., Díaz, M., 2006. Reproduction in an endemic bird of a semiarid island: a food-mediated process. Journal of Avian Biology 37, 447-456. https://doi.org/10.1111/j.2006.0908-8857.03676.x

Kaisin, O., Gazagne, E., Savini, T., Huynen, M.-C., Brotcorne, F., 2018. Foraging strategies underlying bird egg predation by macaques: A study using artificial nests. Am J Primatol 80, e22916. https://doi.org/10.1002/ajp.22916

Kassambara, A., 2020. ggpubr: "ggplot2" Based Publication Ready Plots.

Kay, M., 2020. tidybayes: Tidy Data and Geoms for Bayesian Models. [WWW Document]. URL http://mjskay.github.io/tidybayes/ (accessed 11.29.20).

Khamcha, D., Gale, G., 2020. Predation behaviour of the bridle snake (Lycodon cf. davisonii) on Asian tropical evergreen forest bird nests. The Raffles Bulletin of Zoology. https://doi.org/10.26107/RBZ2020-0091

Khamcha, D., Powell, L.A., Gale, G.A., 2018. Effects of roadside edge on nest predators and nest survival of Asian tropical forest birds. Global Ecology and Conservation 16, e00450. https://doi.org/10.1016/j.gecco.2018.e00450

Knierim, T., Strine, C., Suwanwaree, P., Hill, J., 2019. Spatial ecology study reveals nest attendance and habitat preference of banded kraits (Bungarus fasciatus). Herpetological Bulletin 6-13. https://doi.org/10.33256/hb150.613

Kotler, B.P., Blaustein, L., Brown, J.S., 1992. Predator facilitation: the combined effect of snakes and owls on the foraging behavior of gerbils. Annales Zoologici Fennici 29, 199-206.

Kranstauber, B., Kays, R., LaPoint, S.D., Wikelski, M., Safi, K., 2012. A dynamic Brownian bridge movement model to estimate utilization distributions for heterogeneous animal movement: The dynamic Brownian bridge movement model. Journal of Animal Ecology 81, 738-746. https://doi.org/10.1111/j.1365-2656.2012.01955.x

Kranstauber, B., Smolla, M., Scharf, A.K., 2020. move: Visualizing and Analyzing Animal Track Data.

Lardner, B., Savidge, J.A., Reed, R.N., Rodda, G.H., 2014. Movements and Activity of Juvenile Brown Treesnakes (Boiga irregularis). Copeia 2014, 428-436. https://doi.org/10.1643/CE-14-050

Lemon, J., Bolker, B., Oom, S., Klein, E., Rowlingson, B., Wickham, H., Tyagi, A., Eterradossi, O., Grothendieck, G., Toews, M., Kane, J., Turner, R., Witthoft, C., Stander, J., Petzoldt, T., Duursma, R., Biancotto, E., Levy, O., Dutang, C., Solymos, P., Engelmann, R., Hecker, M., Steinbeck, F., Borchers, 
H., Singmann, H., Toal, T., Ogle, D., Baral, D., Groemping, U., Venables, B., 2020. plotrix: Various Plotting Functions.

Lüdecke, D., Makowski, D., Waggoner, P., Patil, I., 2020. perfomance: Assessment of Regression Models Performance [WWW Document]. URL https://easystats.github.io/performance/ (accessed 11.29.20).

Lutterschmidt, W.I., 1994. The effect of surgically implanted transmitters upon the locomotory performance of the checkered garter snake, Thamnophis m marcianus. The Herpetological Journal 4, 11-14.

Mackessy, S.P., 2002. Biochemistry and pharmacology of Colubrid snake venoms. Journal of Toxicology: Toxin Reviews 21, 43-83. https://doi.org/10.1081/TXR-120004741

Maechler, M., Rousseeuw, P., Struyf, A., Hubert, M., Hornik, K., 2019. cluster: Cluster Analysis Basics and Extensions.

Marshall, B.M., Crane, M., Silva, I., Strine, C.T., Jones, M.D., Hodges, C.W., Suwanwaree, P., Artchawakom, T., Waengsothorn, S., Goode, M., 2020. No room to roam: King Cobras reduce movement in agriculture. Mov Ecol 8, 33-47. https://doi.org/10.1186/s40462-020-00219-5

Martin, T.E., 1993. Nest Predation and Nest Sites. BioScience 43, 523-532. https://doi.org/10.2307/1311947

Meredith, M., Bryer (showShinyApp), J., Kruschke, J., Neelon (Bnormal), B., Schaub (ch2mArray), M., AICC), R.C.T. (stats::AIC code adapted for, 2020. wiqid: Quick and Dirty Estimates for Wildlife Populations.

Mullin, S.J., Cooper, R.J., 1998. The Foraging Ecology of the Gray Rat Snake (Elaphe obsoleta spiloides) Visual Stimuli Facilitate Location of Arboreal Prey. The American Midland Naturalist 140, 397-401. https://doi.org/10.1674/0003-0031(1998)140[0397:TFEOTG]2.0.CO;2

Newmark, W.D., Stanley, T.R., 2011. Habitat fragmentation reduces nest survival in an Afrotropical bird community in a biodiversity hotspot. Proceedings of the National Academy of Sciences 108, 1148811493. https://doi.org/10.1073/pnas.1104955108

Pedersen, T.L., Crameri, F., 2020. scico: Colour Palettes Based on the Scientific Colour-Maps.

Peterson, R.A., Cavanaugh, J.E., 2020. Ordered quantile normalization: a semiparametric transformation built for the cross-validation era. Journal of Applied Statistics 47, 2312-2327. https://doi.org/10.1080/02664763.2019.1630372

Pierce, A.J., Pobprasert, K., 2013. Nest predators of southeast Asian evergreen forest birds identified through continuous video recording. Ibis 155, 419-423. https://doi.org/10.1111/ibi.12033

Pierce, A.J., Pobprasert, K., 2007. A portable system for continuous monitoring of bird nests using digital video recorders. J Field Ornithology 78, 322-328. https://doi.org/10.1111/j.15579263.2007.00119.x

Pierce, A.J., Sankamethawee, W., Powell, L.A., Gale, G.A., 2020. Patterns of nesting and nest success in an evergreen forest in Southeast Asia. Emu - Austral Ornithology 120, 46-55. https://doi.org/10.1080/01584197.2019.1686645 
Pleguezuelos, J.M., Fernández-Cardenete, J.R., Honrubia, S., Feriche, M., Villafranca, C., 2007. Correlates between morphology, diet and foraging mode in the Ladder Snake Rhinechis scalaris (Schinz, 1822). Contributions to Zoology 76, 179-186. https://doi.org/10.1163/18759866-07603003

R Core Team, 2020. R: a language and environment for statistical computing. https://www.r-project.org/

R Studio Team, 2020. RStudio: integrated development environment for R. http://www.rstudio.com/

Reinert, H.K., Cundall, D., 1982. An Improved Surgical Implantation Method for Radio-Tracking Snakes. Copeia 1982, 702-705. https://doi.org/10.2307/1444674

Reinert, H.K., Cundall, D., Bushar, L.M., 1984. Foraging Behavior of the Timber Rattlesnake, Crotalus horridus. Copeia 1984, 976. https://doi.org/10.2307/1445342

Remeš, V., Matysioková, B., Cockburn, A., 2012. Long-term and large-scale analyses of nest predation patterns in Australian songbirds and a global comparison of nest predation rates. Journal of Avian Biology 43, 435-444. https://doi.org/10.1111/j.1600-048X.2012.05599.x

Ribeiro-Silva, L., Perrella, D.F., Biagolini-Jr, C., Zima, P., Piratelli, A.J., Schlindwein, M., Galetti-Jr, P., Francisco, M., 2018. Testing camera traps as a potential tool for detecting nest predation of birds in a tropical rainforest environment. Zoologia 35, 1-8. https://doi.org/10.3897/zoologia.35.e14678

Ridout, M., Linkie, M., 2009. Estimating overlap of daily activity patterns from camera trap data. Journal of Agricultural, Biological and Environmental Statistics 14, 322-337.

Robinson, W.D., Rompré, G., Robinson, T.R., 2005. Videography of Panama bird nests shows snakes are principal predators. Ornitologia Neotropical 16, 187-195.

Rodda, G., 1992. Foraging behaviour of the brown tree snake, Boiga irregularis. Herpetol. J. 2, 110-114.

Rodda, G.H., Fritts, T.H., Conry, P.J., 1992. Origin and Population Growth of the Brown Tree Snake, Boiga irregularis, on Guam. Pacific Science 46, 46-57.

Saenz, D., Fitzgerald, L.A., Baum, K.A., Conner, R.N., 2006. Abiotic correlates of anuran calling phenology: the importance of rain, temperature, and season. Herpetological Monographs 20(1): 64-82.

Santana-Bendix, M.A., 1994. Movements, activity patterns and habitat use of Boiga irregularis (Colubridae), an introduced predator in the island of Guam.

Savidge, J.A., 1988. Food Habits of Boiga irregularis, an Introduced Predator on Guam. Journal of Herpetology 22, 275-282. https://doi.org/10.2307/1564150

Schaefer, W.H., 1934. Diagnosis of Sex in Snakes. Copeia 1934, 181-181. https://doi.org/10.2307/1435852

Sekercioglu, C.H., Daily, G.C., Ehrlich, P.R., 2004. Ecosystem consequences of bird declines. Proceedings of the National Academy of Sciences 101, 18042-18047. https://doi.org/10.1073/pnas.0408049101

Shine, R., 1991. Why do Larger Snakes Eat Larger Prey Items? Functional Ecology 5, 493-502. https://doi.org/10.2307/2389631

Siers, S.R., Barnhart, P.D., Shiels, A.B., Rabon, J.A.B., Volsteadt, R.M., Chlarson, F.M., Larimer, J.R., Dixon, J.C., Gosnell, R.J., 2018. Monitoring Brown Treesnake Activity Before and After an Automated Aerial Toxicant Treatment 16. 
Silva, I., Crane, M., Suwanwaree, P., Strine, C., Goode, M., 2018. Using dynamic Brownian Bridge Movement Models to identify home range size and movement patterns in king cobras. PLoS ONE 13, e0203449. https://doi.org/10.1371/journal.pone.0203449

Smith, S.N., Jones, M.D., Marshall, B.M., Waengsothorn, S., Gale, G.A., Strine, C.T., 2020. Restricted constrictors: Space use and habitat selection of native Burmese pythons in Northeast Thailand (preprint). Ecology. https://doi.org/10.1101/2020.09.17.302661

Somsiri, K., Gale, G.A., Pierce, A.J., Khamcha, D., Sankamethawee, W., 2020. Habitat structure affects nest predation of the Scaly-crowned Babbler (Malacopteron cinereum) by macaques and snakes in a Thai-seasonal evergreen forest. J Ornithol 161, 389-398. https://doi.org/10.1007/s10336-01901724-0

Sperry, J.H., Cimprich, D.A., Peak, R.G., Weatherhead, P.J., 2009. Is nest predation on two endangered bird species higher in habitats preferred by snakes? Écoscience 16, 111-118. https://doi.org/10.2980/16-1-3198

Sperry, J.H., Peak, R.G., Cimprich, D.A., Weatherhead, P.J., 2008. Snake Activity Affects Seasonal Variation in Nest Predation Risk for Birds. Journal of Avian Biology 39, 379-383.

Sperry, J.H., Weatherhead, P.J., 2009. Does Prey Availability Determine Seasonal Patterns of Habitat Selection in Texas Ratsnakes. Journal of Herpetology 43, 55-64. https://doi.org/10.1670/08$058 R 1.1$

Thompson, F.R., 2007. Factors affecting nest predation on forest songbirds in North America. Ibis 149, 98109. https://doi.org/10.1111/j.1474-919X.2007.00697.x

Tobin, M.E., Sugihara, R.T., Pochop, P.A., Linnell, M.A., 1999. Nightly and Seasonal Movements of Boiga irregularis on Guam. Journal of Herpetology 33, 281-291. https://doi.org/10.2307/1565725

Ujvari, B., Korsos, Z., 2000. Use of radiotelemetry in snakes: a review. Acta Zoologica Academiae Scientiarum Hungaricae 46, 115-146.

Venables, W., Ripley, B., 2002. Modern Applied Statistics with S., Fourth Edition. ed. Springer New York, New York, NY.

Weatherhead, P.J., Blouin-Demers, G., 2004. Understanding avian nest predation: why ornithologists should study snakes. Journal of Avian Biology 35, 185-190. https://doi.org/10.1111/j.09088857.2004.03336.x

Weatherhead, P.J., Charland, M.B., 1985. Habitat Selection in an Ontario Population of the Snake, Elaphe obsoleta. Journal of Herpetology 19, 12-19. https://doi.org/10.2307/1564415

Webster, M.M., Rutz, C., 2020. How STRANGE are your study animals? Nature 582, 337-340. https://doi.org/10.1038/d41586-020-01751-5

Whitaker, P.B., Shine, R., 2003. A radiotelemetric study of movements and shelter-site selection by freeranging Brownsnakes (Pseudonaja textilis, Elapidae). Herpetological Monographs 17, 130-144. https://doi.org/10.1655/0733-1347(2003)017[0130:ARSOMA]2.0.CO;2

Wickham, H., 2016. Elegant Graphics for Data Analysis. Springer-Verlag New York, New York, NY.

Wickham, H., 2007. Reshaping Data with the reshape Package. Journal of Statistical Software 21, 1-20. https://doi.org/10.18637/jss.v021.i12 
Wickham, H., François, R., Henry, L., Müller, K., RStudio, 2020. dplyr: A Grammar of Data Manipulation.

Wickham, H., Pedersen, T.L., 2019. gtable: Arrange “Grobs” in Tables.

Wickham, H., Seidel, D., 2020. scales: Scale Functions for Visualization.

Wilke, C.O., 2020a. cowplot: Streamlined Plot Theme and Plot Annotations for "ggplot2."

Wilke, C.O., 2020b. ggridges: Ridgeline Plots in "ggplot2."

Wilke, C.O., 2020c. ggtext: Improved Text Rendering Support for "ggplot2." 